\title{
Arctic future scenario experiments with a coupled regional climate model
}

\section{Torben Koenigk, Ralf Do“Scher \& Grigory Nikulin}

To cite this article: Torben Koenigk, Ralf Do"Scher \& Grigory Nikulin (2011) Arctic future scenario experiments with a coupled regional climate model, Tellus A: Dynamic Meteorology and Oceanography, 63:1, 69-86, DOI: 10.1111/j.1600-0870.2010.00474.x

To link to this article: https://doi.org/10.1111/j.1600-0870.2010.00474.x

\section{(c) 2010 The Author(s). Published by Taylor \& Francis.}

\section{Published online: 15 Dec 2016.}

Submit your article to this journal

\section{山 Article views: 14}

Q View related articles $₫$

4 Citing articles: 3 View citing articles 진 


\title{
Arctic future scenario experiments with a coupled regional climate model
}

\author{
By TORBEN KOENIGK*, RALF DÖSCHER and GRIGORY NIKULIN, Rossby Centre, Swedish \\ Meteorological and Hydrological Institute, 60176 Norrköping, Sweden
}

(Manuscript received 29 September 2009; in final form 4 June 2010)

\begin{abstract}
A number of regional Arctic dynamical downscaling scenario experiments are performed with the Rossby Centre Atmosphere Ocean climate model. The simulations are based on IPCC AR4 scenario simulations with the global coupled models BCCR2.0 and ECHAM5/MPI-OM and differ in the surface salinity treatment and lateral boundary conditions.

Compared to the global runs, the regional simulations show a warmer Arctic, which agrees better to ERA-40 reanalysis data in the 20th century, and a slightly smaller trend in the 21st century. The ECHAM-forced runs show several periods with rapid summer sea ice reductions and partial recovery thereafter. Summer sea ice disappears for the first time around 2040 .

The large-scale change patterns of sea level pressure (SLP) and air temperature in the regional simulations are mainly dominated by the forcing of the global models but locally significant modifications occur. Pressure is reduced by $1-3 \mathrm{hPa}$ and air temperature increases by $2-4 \mathrm{~K}$ in most Arctic regions and up to $10 \mathrm{~K}$ where winter sea ice disappears.

The largely reduced Arctic sea ice area leads to increased atmospheric variability and more extremes in winter SLP and summer air temperature.
\end{abstract}

\section{Introduction}

The Arctic Ocean and the Nordic Seas play an important role in the global climate system. As an interface between atmosphere and ocean, the rather thin layer of sea ice controls most of the fluxes of heat, momentum and matter in ice-covered regions. Small changes in the sea ice cover strongly affect these fluxes and may have a large impact on local and large-scale atmospheric circulation (Alexander et al., 2004; Magnusdottir et al., 2004; Koenigk et al., 2006; Koenigk et al., 2009). Furthermore, the Arctic/Nordic Seas area shows a high sensitivity to climate change. Observations show a substantial reduction of Arctic sea ice in the last $30 \mathrm{yr}$ (Parkinson et al., 1999) and the largest warming rates on the Earth (Serreze et al., 2000; Polyakov et al., 2003).

The resolution of most global climate models is too coarse to adequately resolve important processes such as deep water convection, sea ice melting/freezing, ocean-sea ice-atmosphere interactions at the ice edge and topograpical/orographical influence on the flow of water and air. As these essential processes are strongly non-linear, climate simulations in the Arctic

\footnotetext{
* Corresponding author. e-mail: Torben.Koenigk@smhi.se DOI: $10.1111 /$ j.1600-0870.2010.00474.x
}

regions suffer from large uncertainties, especially due to processes involving sea ice. Global climate models used in the last IPCC-report are not able to simulate the observed negative trend in sea ice cover (Stroeve et al., 2007). This problem has been highlighted recently by the observed extremely low Arctic sea ice extent during late summer 2007 and 2008 (Comiso et al., 2008; Perovich et al., 2008; Zhang et al., 2008), which was not expected. Only two global models were able to simulate comparable rapid change events in near future and thus in a climatic similar sense (Holland et al., 2006).

Regionally coupled Arctic simulations allow for a higher spatial resolution and thus potentially improved representation of many relevant processes although even regional models still are too coarse to resolve small-scale processes. Coupled Arctic models with Pan-Arctic domain have been demonstrated skill for the long-term development of sea ice conditions under recent climate conditions when driven with reanalysis products (Dorn et al., 2008; Döscher et al., 2010). Due to regional domain limits, process studies can be carried out under controlled large-scale conditions.

Sensitivities of Arctic simulations to physical parametrizations and internal variability are still high (Dorn et al., 2007) and so is the associated uncertainty. Results by Mikolajewicz et al. (2005) and Döscher et al. (2010) with a regional coupled model show that the internal climate variability within the Arctic 


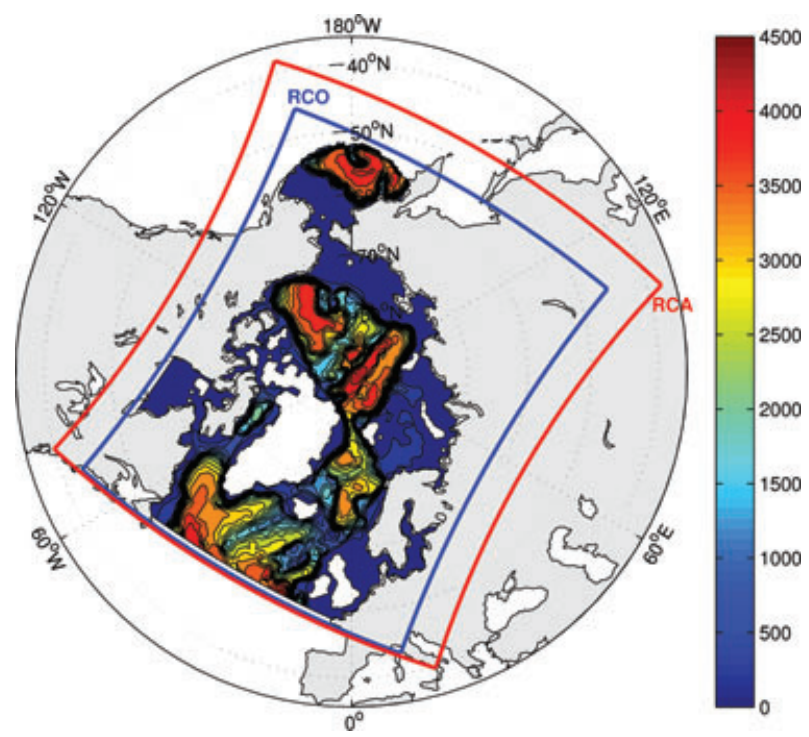

Fig. 1. RCAO domain and orography (depth in $\mathrm{m}$, taken from Döscher et al., 2010).

is substantial and of the same order of magnitude as the external variability forced from the lateral boundary conditions. This underlines the need of an ensemble approach for regional Arctic simulations.

After model validation and process studies (Döscher et al., 2010), here we present the first coupled regional Arctic future scenario experiments. An ensemble of six experiments has been carried out with the Rossby Centre Atmosphere Ocean Model RCAO. We aim at an Arctic regionalization of global climate change scenarios for the purpose of improving our understanding of coupled processes under the conditions of changing global climate and for providing better resolved physical fields of possible future climates to the impact community.

The article is organized as follows: the following section gives a description of the model and describes the scenario experiments. Sections 3 describes the development of sea ice, ocean and atmosphere parameters in the Arctic in the different experiments and compare them to each other and to the original global coupled scenarios. In the final section, results are summarized and discussed.

\section{Model and experiments}

\subsection{The RCAO model}

The regional Arctic scenario simulations are performed with the Rossby Centre Atmosphere Ocean model RCAO (Döscher et al., 2002; Döscher et al., 2010), which consists of the atmosphere component RCA and the ocean component RCO. The model area extends from about $50^{\circ} \mathrm{N}$ in the Atlantic sector across the Arctic to the Aleutian Islands in the North Pacific as described in Fig. 1. Both RCO and RCA run in a horizontal resolution of $0.5^{\circ}$ on a rotated latitude-longitude grid with the grid equator crossing the geographical North Pole.

The ocean component RCO has been described and validated for the Arctic (Döscher et al., 2010) and for a Baltic Sea domain (Meier et al., 2003). RCO incorporates a dynamic-thermodynamic sea ice model based on an elasticviscous-plastic (EVP) rheology (Hunke and Dukowicz, 1997) and a Semtner-type thermodynamics (Semtner, 1976). The ice and snow albedo formulation is based on a modified version of Koltzow (2007) with albedo values dependent on the ice surface temperature. A parametrization for melt ponds is included.

RCO has 59 unevenly spaced vertical levels. A closed lateral boundary exists at the Aleutian Island chain and open lateral boundary conditions in the North Atlantic Ocean. In the case of inflowing water, climatologically monthly mean temperature and salinity data from the PHC data set (Steele et al., 2001) and monthly ocean data from global scenario simulations of the German Max Planck Institute climate model ECHAM5/MPIOM are used. The PHC climatology is used for restoring sea surface salinity on a timescale of $240 \mathrm{~d}$. This type of restoring is necessary to prevent artificial salinity drift due to insufficient description of freshwater runoff and precipitation. In this paper, we also test the effect of a salinity flux correction instead of the relaxation.

The atmosphere component RCA has been described by Jones et al. (2004a, b) and Kjellström et al. (2005). The current model set up has 24 vertical layers in terrain-following hybrid coordinates with a model top at approximately $15 \mathrm{hPa}$. As lateral boundary forcing, atmospheric data from ECHAM5/MPI-OM and BCCR2.0 are taken and updated with a 6-hourly frequency. Recent improvements of RCA are described in Kjellström et al. (2005); Samuelsson et al. (2006) and Döscher et al. (2010).

Both models RCO and RCA exchange information via a separate coupler software OASIS4 (Valcke and Redler, 2006) with a coupling frequency of three hours.

\subsection{Experiments}

A number of scenario experiments are performed with RCAO. Regional simulations start on 1 April 1960 and end on 31 December 2080. All regional runs were initialized with ERA40 atmospheric fields and ocean temperature and salinity from the PHC climatology (Steele et al. 2001). Sea ice was initialized with a constant thickness of $2.3 \mathrm{~m}$ and a concentration of $95 \%$ for ocean gridboxes with a sea surface temperature (SST) colder or equal to the freezing temperature. After $20 \mathrm{yr}$ of simulation between 1960 and 1979, the ocean fields are considered in advective balance. As shown in Döscher et al. (2010), trend and mean values of sea ice extent after $20 \mathrm{yr}$ of integration is very much similar to observations during the 1980s and 1990s, when RCAO is forced with ERA-40 reanalysis at the lateral boundaries. 
Our regional future simulations use A1B scenario simulations of the last IPCC Assessment Report from BCCR2.0 and ECHAM5/MPI-OM as forcing at the lateral boundaries of the RCAO model. Also within the regional model area, we prescribed the temporal changes in the atmospheric constituents according to the A1B scenario. In a first step, only the atmosphere fields of the global climate model (GCM) are used while the ocean boundaries are prescribed using climatological values. Additionally, simulations have been performed with forcing from both ocean and atmosphere of ECHAM5/MPI-OM. This allows for analysing the impact of the North Atlantic Ocean boundary conditions on Arctic climate. For each of the different forcings, we perform two regional simulations, which differ in the treatment of the surface salinity in the Arctic. To prevent artificial drift, a salinity restoring to 20th century climatology is used in the first run (ECHstand, BCMstand and ECHMPIstand). The second run uses a monthly mean constant salinity flux correction (ECHflux, BCMflux and ECHMPIflux), which allows for more realistic salinity variability in the future. The mean monthly salinity corrections have been derived from RCAO simulations forced with the respective global model with salinity restoring. The mean restoring in the period 1980-2000 has been calculated for each calendar month and is used as salinity flux correction in all flux-simulations. The results of all simulations are compared to each other and to the original data of the global models (ECH_GCM, BCM_GCM).

The 1960 conditions in the AR4 global simulations differ from that of the regional simulations because we used existing global simulations for the downscaling and the global models provide a different present-day climate as RCAO. This might lead to different future responses in the global and the regional simulations.

An overview of the experiments is given in Table 1.

\section{Results of future simulations}

\subsection{Changes in the mean state}

3.1.1. Integrated time series. Figure 2 shows the annual mean air temperature averaged over the entire RCAO domain, the ocean and the land part. Both the ECH_GCM and particularly the BCM_GCM simulate a colder climate than ERA40reanalysis data. BCM_GCM is both over land and ocean about
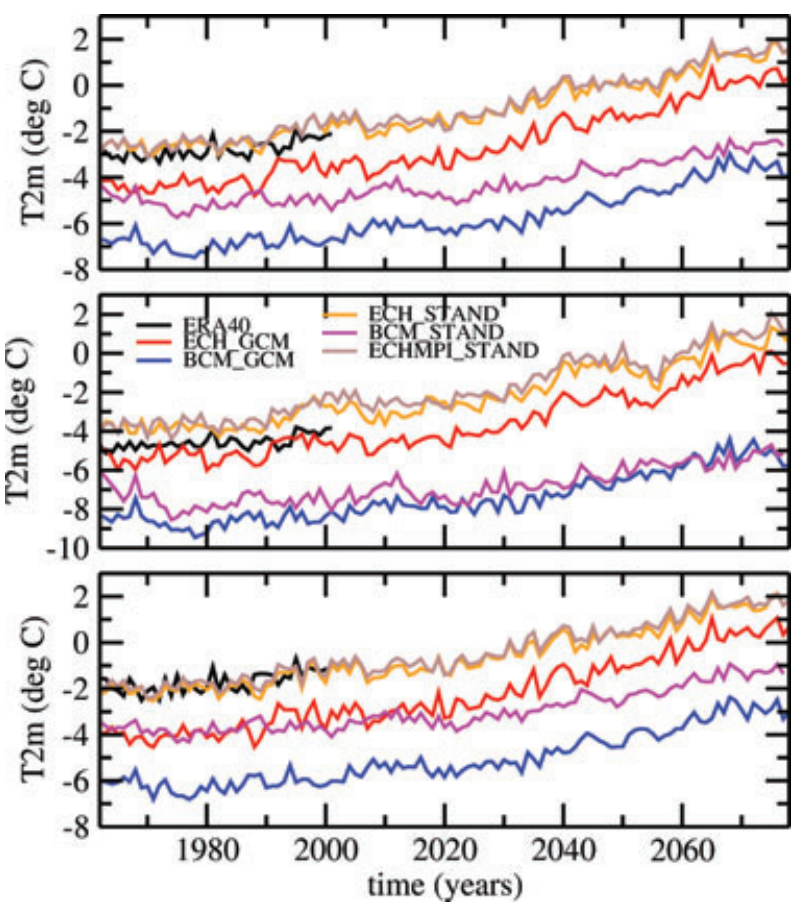

Fig. 2. Annual mean $2 \mathrm{~m}$ air temperature in ${ }^{\circ} \mathrm{C}$, averaged over the entire RCA-domain (top panel), only the ocean area (middle) and only the land area of the RCA-domain (bottom panel).

$4 \mathrm{~K}$ colder than ERA40 while ECH_GCM is only slightly colder over the ocean part but about $2 \mathrm{~K}$ colder over land. The cold bias of BCM_GCM is much more pronounced in winter than in summer (not shown). The regional simulations are generally warmer than the corresponding global runs. However, the BCM-forced simulations are still about $2 \mathrm{~K}$ colder than ERA40. The domainaveraged temperature in the regional $\mathrm{ECH}$-forced runs compare well to the ERA40 data. The change in the salinity treatment does not have a significant impact on the mean temperature and the ECHMPI-runs (with lateral ocean scenario forcing) are only slightly warmer than the ECH-runs. Over the oceans, ECHMPIstand is several tenths of a degree warmer than ECHstand between 2000 and 2080. However, the difference is not growing with time and therefore the ocean boundary forcing of the global scenarios seems to be of limited importance for Arctic climate change.

Table 1. Scenario experiments performed with RCAO

\begin{tabular}{ll}
\hline Experiment name & Description \\
\hline BCMstand & Atm: BCCR2.0 Oce: PHC-climatol., surface salinity restoring \\
BCMflux & Atm: BCCR2.0 Oce: PHC-climatol., surface salinity restoring replaced by surface salinity flux correction \\
ECHstand & Atm: ECHAM5/MPI-OM Oce: PHC-climatol., surface salinity restoring \\
ECHflux & Atm: ECHAM5/MPI-OM Oce: PHC-climatol., surface salinity restoring replaced by surface salinity flux correction \\
ECHMPIstand & Atm: ECHAM5/MPI-OM Oce: ECHAM5/MPI-OM, surface salinity restoring \\
ECHMPIflux & Atm: ECHAM5/MPI-OM Oce: ECHAM5/MPI-OM, surface salinity restoring replaced by surface salinity flux correction \\
\hline
\end{tabular}


The annual mean temperature average over the entire domain increases by about 3.5 and $4.5 \mathrm{~K}$ between the $1980 \mathrm{~s}$ and $2070 \mathrm{~s}$ in BCM_GCM and ECH_GCM, respectively. The warming in winter is generally larger than in summer, both in GCM and RCM runs. In winter, it reaches more than $6 \mathrm{~K}$ in ECH_GCM and about $5 \mathrm{~K}$ in BCM_GCM and 2.5 and $2 \mathrm{~K}$ in summer, respectively (not shown). This is in line with most of the IPCC-AR4 simulations. Chapman and Walsh (2007) analysed 14 IPCC AR4-models and found a warming of 2-7 K north of $60^{\circ} \mathrm{N}$ until 2060-2080 and a much larger warming in winter than in summer. Particularly over land, the trend in our regional simulations is somewhat smaller than in the global models. Both regional and global simulations show inter-annual variability, which is superimposed on the trend. The simulated temperatures in the regional runs are highly correlated to their corresponding GCM-run.

A power spectrum analysis of the detrended time series (not shown) indicates significant decadal variability over the ocean part but not over the land regions. The time series of $2 \mathrm{~m}$ air temperature averaged over the ocean in ECH_GCM and all ECHforced simulations show significant (at 95\% level) peaks at 3-4, 20 and $35 \mathrm{yr}$ and a peak at $8 \mathrm{yr}$ slightly below $95 \%$ significance. The land time series miss both the 8 -yr and 20-yr peaks and the peak at $35 \mathrm{yr}$ is not significant at the $95 \%$ level. The BCM simulations show peaks at similar time periods: the ocean time series show peaks at about 3,6-7 (not significant at 95\%) and $20 \mathrm{yr}$ while the land time series misses the 20 -yr peak.

The spectrums of the global and corresponding regional simulations are almost identically. This would lead to the conclusion that the variability in $2 \mathrm{~m}$ air temperature in the Arctic is mainly governed by the lateral atmospheric boundaries. On the other side, the spectra of the BCM and ECHAM forced simulations also show similarities, which might indicate that the variability is internally generated in the Arctic. Indeed a number of other studies found peaks for Arctic climate variables at time periods of about one decade (e.g. Hilmer and Lemke, 2000; Venegas and
Mysak, 2000) and two decades (e.g. Goosse et al., 2002; Divine and Dick, 2006).

A recent publication by Döscher et al. (2010) showed that RCAO forced with ERA40 data simulated the observed trend in sea ice extent during the 1980s and 1990s well. Figure 3 shows the September sea ice extent in the global BCM and ECHAM5/MPI-OM simulations and in the downscaled scenarios with RCAO. Both BCM_GCM and ECH_GCM simulate a too large Arctic sea ice extent for the 20th century compared to satellite observations (Cavalieri et al., 1996). In the 21st century, BCM_GCM shows only a small negative trend while sea ice extent is strongly reduced in ECH_GCM and summers are almost ice-free at 2080.

In the regional BCM-downscalings, both trend and variability are largely similar to the original simulation. Not before the second half of the 21 st century, the ice extent reaches values similar to recent observations. Interestingly, this is different in the ECH-downscalings: although, sea ice extent in the original ECH_GCM is also too high in the 20th century, the regional simulations show a much smaller sea ice extent, which is even slightly below the observed values. Taking into account that BCM_GCM provides colder lateral boundary conditions than ECH_GCM, it is not surprising that the ECHAM-forced RCAO simulations show a smaller sea ice area than the BCM-forced simulations. The large-scale atmospheric circulation as provided at the lateral boundaries of the RCM (rather than the GCM ice fields) set the stage for the possibilities of the RCM to respond in terms of sea ice conditions. As in ECH_GCM, the ECH-based downscaling trends are strongly negative and the Arctic is for the first time almost ice-free $\left(<1 \mathrm{Mill} \mathrm{km}^{2}\right)$ in late summer around 2040. From 2060 onwards, the Arctic is continuously nearly ice-free in late summer.

The variability is much larger in the regional $\mathrm{ECH}$-simulations than in ECH_GCM. Most important, some rapid change events occur with partial recovery thereafter. Both cannot be found in

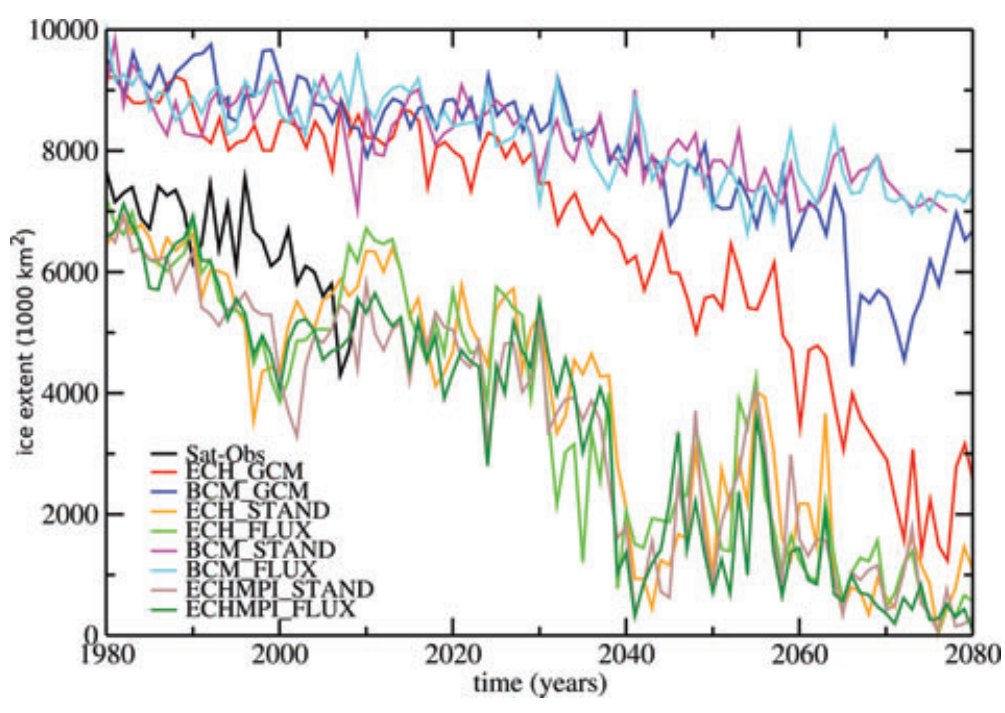

Fig. 3. Arctic September sea ice extent for the regional simulations, the original global simulations and satellite observations (Cavalieri et al., 1996) in $10^{3} \mathrm{~km}^{2}$. 

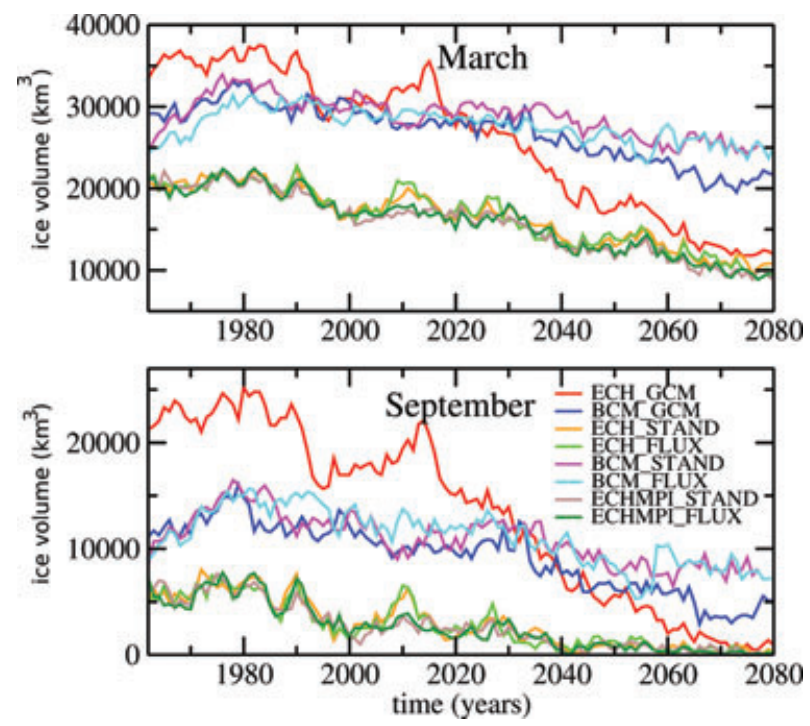

Fig. 4. Sea ice volume in $\mathrm{km}^{3}$ in March (top panel) and September (bottom panel) in the global and the regional simulations. Sum of the entire RCO model domain.

the global simulations. The first event occur at year 2000 in all regional ECH-runs and is of about the same magnitude as the observed summer 2007 event (Comiso et al., 2008). The mechanisms of sea ice reduction and recovery events and comparison to the mechanisms of the 2007 event will be subject of a future study.

The variations between regional simulations belonging to the same GCM are small compared to the differences between regional simulations forced by different global models.

The increased ice extent variability in the regional compared to the global ECH-simulation can be understood by analysing the Arctic ice volume (Fig. 4).

It is given here within the limited regional domain and does not include the entire Northern Hemisphere ice volume.

ECH_GCM has a much larger ice volume and thus much thicker ice in the 20th century in the Arctic compared to all regional simulations and even thicker than BCM_GCM. Analyses of Gerdes and Köberle (2007) who analysed sea ice thickness variability in IPCC models in the 20th century show a large spread in simulated Arctic ice volume with annual mean values varying between about 10000 and $50000 \mathrm{~km}^{3}$.

In contrast to sea ice concentration, ice volume variability in ECH_GCM is high and decadal variations agree well with decadal variations in the corresponding regional simulations. Between 1990 and 2000, sea ice volume is strongly reduced but recovers partly until 2014 . Thereafter reduction periods occur until 2020, between 2030-2040 and 2050-2060. While ice volume in the ECH-forced regional simulations still partly recovers between the periods of reduction, there is no recovery in ECH_GCM but a damped reduction in these periods after 2020.
The decadal variations in ECH_GCM ice volume do not lead to significant variations in the ice extent because the ice is also in periods with reduced ice volume still comparably thick. This is different in the regional simulations where the warm period at year 2000 (Fig. 2) is leading to a strong reduction in sea ice extent. Ice extent variability in ECH_GCM increases from 2050 onwards when sea ice becomes thin in ECH_GCM as well.

The warm period around 2000 in the ECH-forced simulations is caused by the large scale dynamic features originating from the atmospheric lateral boundary since all regional ECHAMdownscalings (both fully GCM forced and atmosphere-GCM + ocean climatology) and also ECH_GCM show this warming. Analysis of the spatial $2 \mathrm{~m}$ air temperature anomalies for the mean of the warm period 1992-2006 compared to reference periods of 1960-1990 and 1980-2020 in ECH_GCM (not shown) show a warming over most of the earth, which is largest in the Arctic. The SLP anomalies for the 1992-2006 period show a decrease over the Arctic, which might be a response to the warming, but no indication for strong changes at the RCAO boundaries. This leads us to the conclusion that warmer than normal air masses are advected into the Arctic regions and reduce sea ice extent and volume in the regional simulations and ice volume in ECH_GCM. The sea ice-albedo—feedback might amplify the warming signal or at least conserves the warming signal for some time.

The decadal variability of ice volume in BCM_GCM and the corresponding regional runs is small. BCM_GCM shows an ice volume increase between 1960 and 1980 and thereafter reduction periods in the 1980s, 2000s, 2030s and at 2065. BCM_STAND and BCM_FLUX follow the increase until 1980s but only partly the decrease periods in the 21 st century and end thus with a higher ice volume at 2080 .

In all simulations, the variability is very similar in March and September. The winter-summer difference is almost the same with about $15000 \mathrm{~km}^{3}$.

It is striking that the RCAO downscaling of ECHAM but not the downscaling of $\mathrm{BCM}$ leads to a strong reduction in sea ice volume in comparison to their original global simulations. RCAO produces less ice volume when using the warmer boundary conditions of ECHAM compared to BCM. The question remains why ECHAM simulates a larger sea ice volume than $\mathrm{BCM}$ despite the fact that it shows a warmer Arctic climate. The most probable explanation are differences in the ice models. Since the ice models of ECHAM, BCM and RCAO are based on similar physical equations and similar parametrizations, the differences are probably mainly due to different adjustments of the ice model parameters. Assuming ECHAM, BCM and RCAO would have the same atmospheric and oceanic conditions in the Arctic, BCM would probably simulate the smallest ice volume followed by RCAO and ECHAM would have the largest Arctic ice volume. These results highlight the uncertainty in future sea ice projections. 


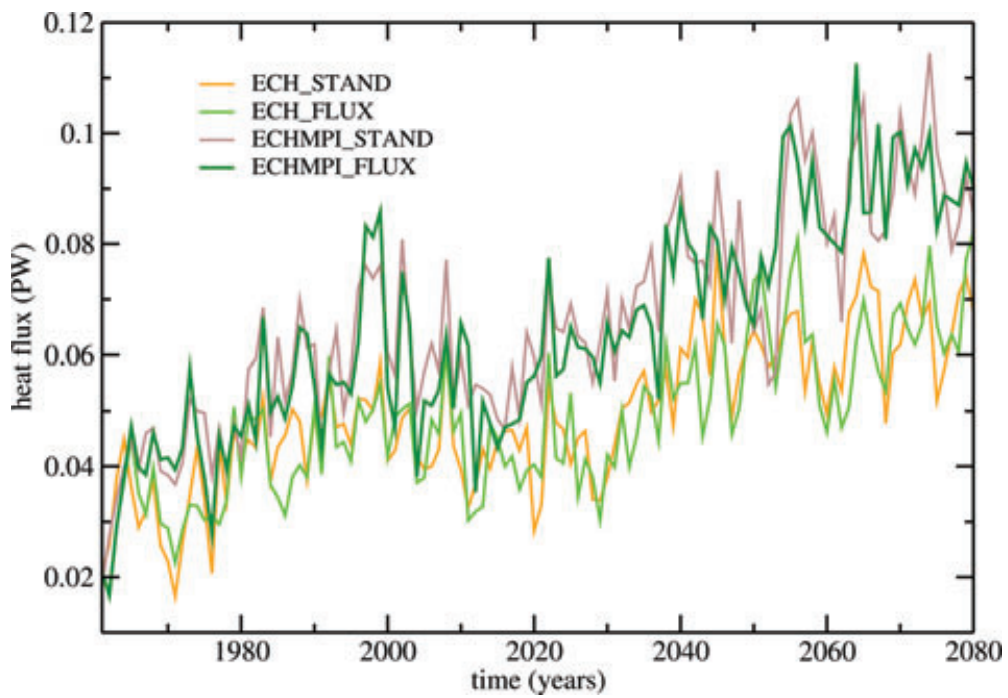

Fig. 5. Annual mean ocean heat flux into the Arctic between the Lofoten Islands $\left(76.49^{\circ} \mathrm{N}, 19.54^{\circ} \mathrm{W}\right.$, Norway) and Danmarkshavn $\left(68.15^{\circ} \mathrm{N}, 13.78^{\circ} \mathrm{E}\right.$, Greenland) in PW.
The discrepancies between the two RCAO versions are very small for both sea ice extent and ice volume. We can conclude that the surface salinity treatment has only limited impact on the models sea ice extent and volume. Also the impact of using the entire GCM-forcing on ice extent and volume is relatively small.

Figure 5 monitors the oceanic heat fluxes that enter the Arctic after passing through the Nordic Seas. For the ECHAM-forced downscaling runs, we present heat fluxes passing through a model longitude section (in rotated coordinates) corresponding to a line between the Lofoten Islands $\left(68.2^{\circ} \mathrm{N}\right.$, $13.8^{\circ} \mathrm{E}$, Norway) and Danmarkshavn, $\left(76.5^{\circ} \mathrm{N}, 19.5^{\circ} \mathrm{W}\right.$, Greenland). The mean heat flux into the Arctic varies about $45 \mathrm{TW}$ in ECHstand and ECHflux and about 60 TW in ECHMPIstand and ECHMPIflux. Results from observations indicate an estimated heat flux into the Arctic of 50-80 TW (Simmons and Haugan, 1996). Model simulations by Maslowski et al. (2004) show an input of $88 \mathrm{TW}$ into the Arctic. The results are not directly comparable since the heat fluxes are not calculated at exactly the same sections. The oceanic heat flux are of about an order of magnitude smaller than the northward atmospheric heat flux but as shown by Jungclaus and Koenigk (2009), decadal variations in ocean and atmosphere heat fluxes are of about the same size.

The interdecadal mean remains about constant until about 2030. Runs with climatological ocean forcing at the Atlantic lateral boundary (ECHstand, ECHflux) show a generally weaker transport compared to those forced with the OGCM (ECHMPIstand, ECHMPIflux). After 2030 both groups of scenarios turn towards increased heat transports, whereby the OGCM-forced runs show a stronger increase. The fact that even the oceanclimatologically forced runs show an increase indicates that enhanced surface heating south of the monitoring section must contribute to the signal. In comparison with the OGCM-forced runs it also becomes clear that the additional lateral warming at the Atlantic boundary gives additional support for increased heat transports towards the Arctic Ocean.
3.1.2. Spatial distribution. In this section, means of the periods 2020-2040 and 2060-2080 are compared with the control period 1980-2000. Furthermore, differences between the response in the regional and global simulations as well as between the different regional simulations are analysed. Two-sided $t$-test are used to find regions, where the regional simulations among each other and the regional simulations and the corresponding global simulation significantly differ.

The results from the integrated time series showed that the ECHAM5/MPI-OM forced simulations compare well to the results from ERA-data in the 20th century. Thus, we will mainly concentrate on these simulations in the following.

Figure 6 show the future changes of sea ice concentration in September in ECH_GCM and the corresponding RCAO downscaling simulations. The change pattern and amplitude differ somewhat between regional and global simulation but in all runs the ice reductions are significant at the $95 \%$ level in most of the Arctic Ocean already in 2020-2040. In ECH_GCM, sea ice concentration is reduced by $10-30 \%$ along the coasts of the Arctic Ocean and up to $40 \%$ in the northwestern part of the Barents Sea. Sea ice concentration retreats significantly faster in the regional ECH-forced runs. Here, the reduction is mainly concentrated on the Beaufort Sea and the western Central Arctic until 2020-2040. The responses in the four regional simulations are similar but reduction of ice concentration is somewhat smaller in ECHstand compared to the other regional runs. In 2060-2080, all regional simulations show an almost ice-free Arctic in September. In contrast ECH_GCM has some ice left in the Central Arctic and North of Greenland. Sea ice concentration is only reduced by $20-40 \%$ in these regions.

The changes in March (not shown) are less severe. The strongest retreats occur in the ECH-simulations in the Barents Sea, Hudson Bay, Labrador Sea and in the Bering Sea. The reduction in the Hudson Bay is generally larger in the regional 
a) Ice concentration, September change, 2020-2040 - 1980-2000

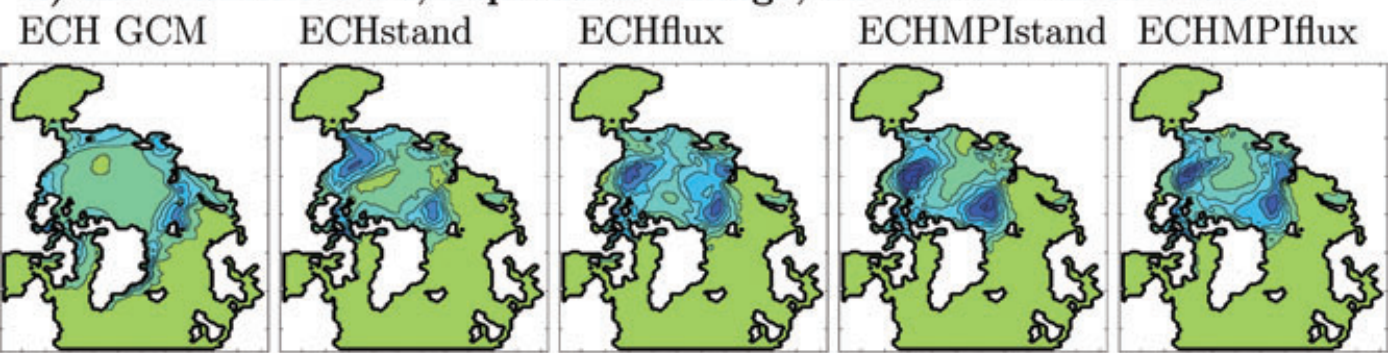

b) Ice concentration, September change, 2060-2080 - 1980-2000

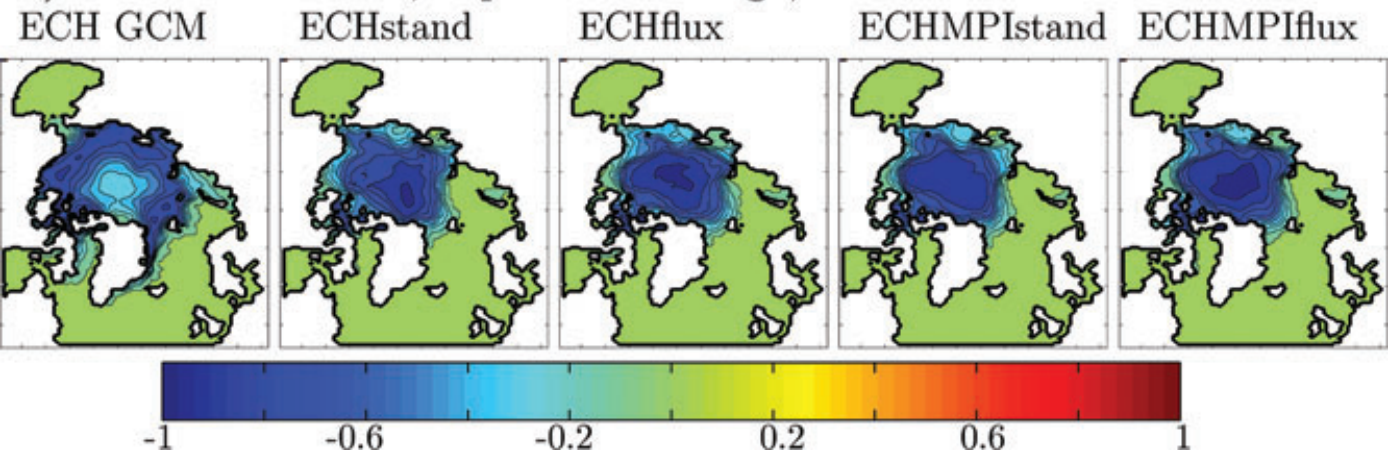

Fig. 6. September ice concentration changes in fraction between (a) 2020-2040 and 1980-2000 and (b) 2060-2080 and 1980-2000 in the regional and global ECH-simulations.

simulations and the reduction of sea ice in the Barents Sea is largest in the ECHflux run.

The change patterns in sea ice thickness (Fig. 7) differ strongly from those of sea ice concentrations. The winter and summer patterns are very similar except for some regions along the ice edges, thus the annual mean is discussed. In contrast to ice concentration, ice thickness reduction is almost twice as large in ECH_GCM as in the respective regional simulations. Also the change patterns differ: ECH_GCM shows the strongest thinning all along the coasts with maximum values of up to $-1.5 \mathrm{~m}$ in the Canadian Archipelago and north of Greenland in the near future (2020-2040). In the regional ECH-simulations, sea ice is strongest reduced at the Siberian coast with about $-0.6 \mathrm{~m}$. The thinning is somewhat more pronounced in the runs with full GCM-forcing at the lateral boundaries compared to atmosphereGCM and ocean-climatology forcing. In addition, there is a tendency to larger thinning in the flux-simulations compared to the standard simulations, which indicates an impact of the salinity description on the ice development. However, due to high sea ice thickness variability compared to the differences between the regional simulations, the differences are not significant at the $95 \%$ level but partly at the $90 \%$ level. The thinning pattern in the regional simulations compares well to an observational based estimated thinning pattern of the period 1987-1999 (Rothrock et al., 2003).

This pattern with a maximum off East Siberia stays similar during the entire 21 st century. However, the amplitudes increase and reach up to $-1.4 \mathrm{~m}$ in ECHstand and $-1.8 \mathrm{~m}$ in ECHMPIflux at the Siberian coast until 2060-2080. In the Central Arctic, ice is thinning by about $1 \mathrm{~m}$. The reduction is much stronger in ECH_GCM with as much as $-3 \mathrm{~m}$ north of Greenland and in the Beaufort Sea.

While discussing the seemingly inconsistency that ice thickness reduction is larger but the decrease in ice concentration smaller in ECH_GCM compared to its regional downscalings we note that sea ice in the 20th century is much thicker in ECH_GCM. This means that ice thickness changes can potentially be larger and that ice concentration is reduced in areas where no or small amounts of sea ice exist in the regional runs.

Interestingly, all regional simulations show an increase of sea ice tickness in the Greenland Sea during 2020-2040. This is also reflected in winter sea ice concentrations (not shown). The mechanism leading to this sea ice increase is the following: the warming reduces sea ice in the Barents Sea, which leads to increased vertical heat fluxes and thus reduced sea level pressure (SLP) in the Barents Sea and north of it (Deser et al., 2004; Magnusdottir et al., 2004). Consequently, northerly and westerly wind anomalies occur in the Greenland Sea, which transports sea ice further to the South and the East. This includes even increased sea ice export through Fram Strait. The sea ice increase is more pronounced in ECHstand and ECHflux than in ECHMPIstand and ECHMPIflux. ECH_GCM does not show any increase although SLP anomalies are similar to the regional simulations. Probably, the inflow of somewhat warmer Atlantic 


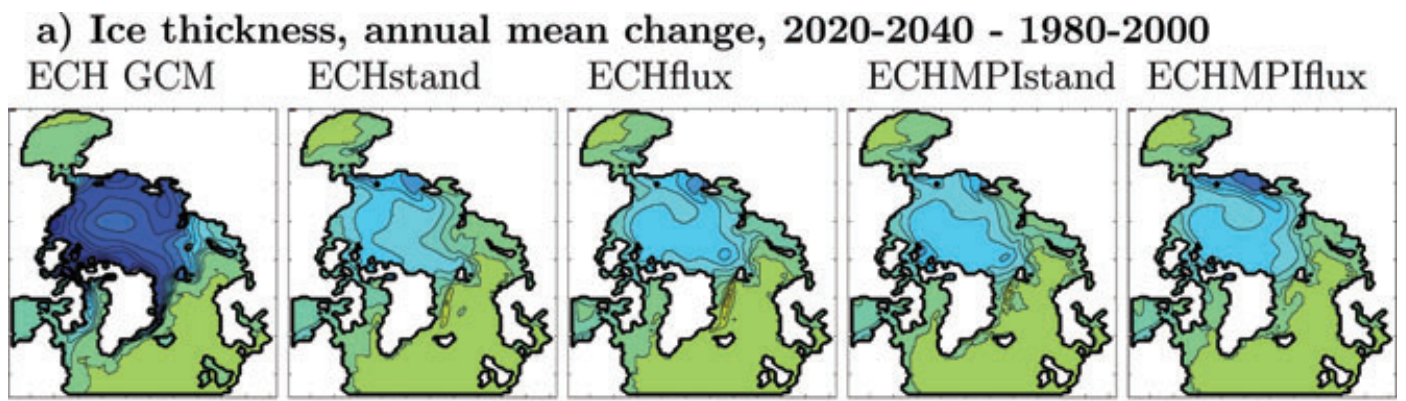

b) Ice thickness, annual mean change, 2060-2080 - 1980-2000
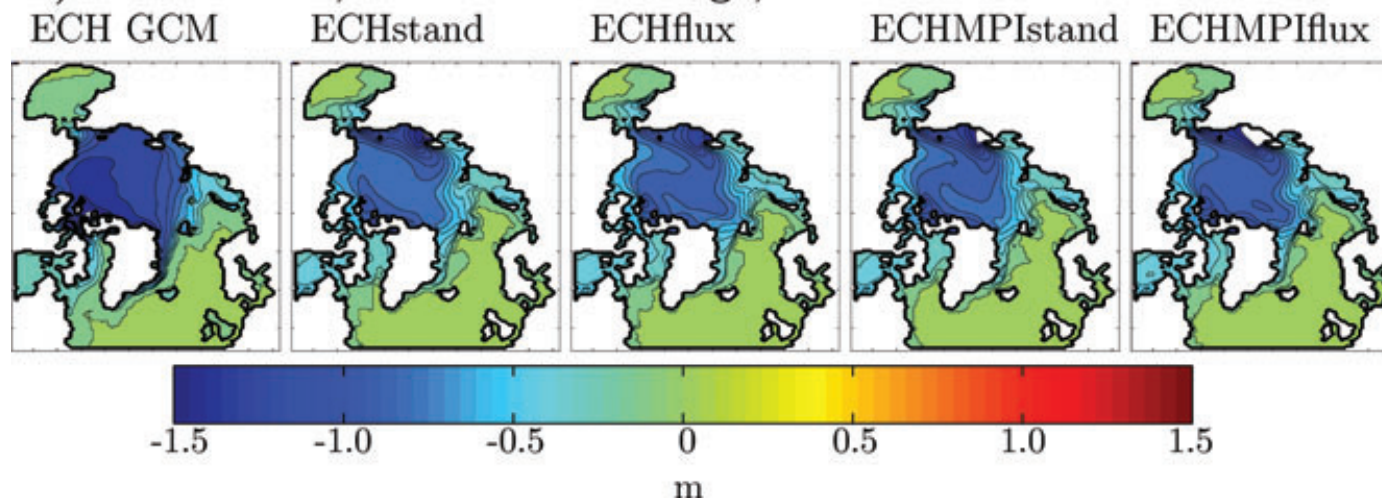

Fig. 7. Annual mean ice thickness changes in meters between (a) 2020-2040 and 1980-2000 and (b) 2060-2080 and1980-2000 in the regional and global ECH-simulations.

water in the ECHMPI-forced runs and ECH_GCM compared to the 20th century climatology cancels the effect of more ice transport by more melting.

Besides increased greenhouse gas concentration with associated radiative effects, future warming in the Arctic depends on the changes in the sea ice distribution and related ocean heat release. A number of studies show strong warming in regions with reduced sea ice. Bengtsson et al. (2004) performed simulations with an AGCM forced with the GISST data set for the 20th century. After 1949, a shift in the procedure in deriving sea ice concentrations in the GISST data leads to a sudden reduction of the sea ice area by $2 \times 10^{6} \mathrm{~km}^{2}$ with largest changes in the Barents Sea. The reduction of sea ice area in the Barents Sea increases winter ocean heat release by up to $150 \mathrm{~W} \mathrm{~m}^{-2}$ and temperature by $6 \mathrm{~K}$. Rinke et al. (2006) analysed the impact of lower-boundary forcing on the mean state of the atmosphere by forcing a regional atmosphere model with two different sets of sea ice and SST. They found that local air temperature is much warmer where sea ice is decreased and the effect is most pronounced close to the ice edge.

These results compare well to our simulated future temperature changes (Fig. 8). The strongest warming occurs in the regions with strongest reduction of sea ice concentration. This is the Barents Sea for ECH_GCM in 2020-2040 where $2 \mathrm{~m}$ air temperature is increased by up to $3 \mathrm{~K}$. The warming in regional runs is even somewhat larger with $4-5 \mathrm{~K}$. Also in the Central Arctic and particularly in the Beaufort Sea, the response is signif- icantly larger in the regional simulations than in ECH_GCM due to stronger sea ice reductions. ECHstand shows slightly smaller warming rates in most of the Arctic compared to the other regional runs. This can be attributed to the somewhat smaller sea ice reduction in ECHstand.

All regional simulations show a temporary cooling in the Greenland Sea and around Iceland due to anomalous northerly winds and increased ice cover in this region. This cooling is more pronounced in the runs with climatological forcing in the ocean than in the fully GCM-forced runs.

In the northeastern North Atlantic, temperature changes are very small and not significant compared to the period 1980-2000.

In 2060-2080, the temperature increases with more than $5 \mathrm{~K}$ in the entire Arctic Ocean in all regional simulations and in ECH_GCM while the northeastern North Atlantic still shows only small warming rates.

The regional simulations show strongest warming in the Central Arctic and North of Fram Strait and Barents Sea with a temperature increase of up to $9 \mathrm{~K}$. In ECH_GCM, two maxima occur: the most pronounced maximum extends from the Fram Strait across the northern Barents Sea to the Laptev Sea with highest warming rates in the northern Kara Sea. A second somewhat smaller maximum occurs along the North American coast. These change patterns can again be attributed to the different response of sea ice concentration. Keup-Thiel et al. (2006) analysed the future climate development in the Barents Sea region 
a) 2m air temp, annual mean change, 2020-2040 - 1980-2000

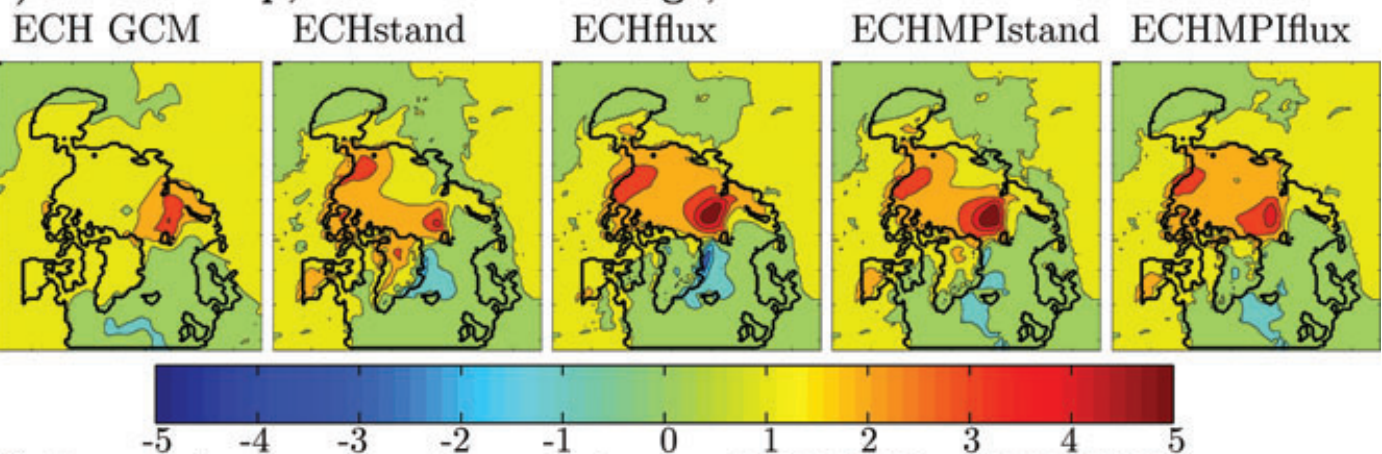

b) $2 \mathrm{~m}$ air temp, annual mean change, 2060-2080 - 1980-2000 ECH GCM ECHstand ECHflux ECHMPIstand ECHMPIflux
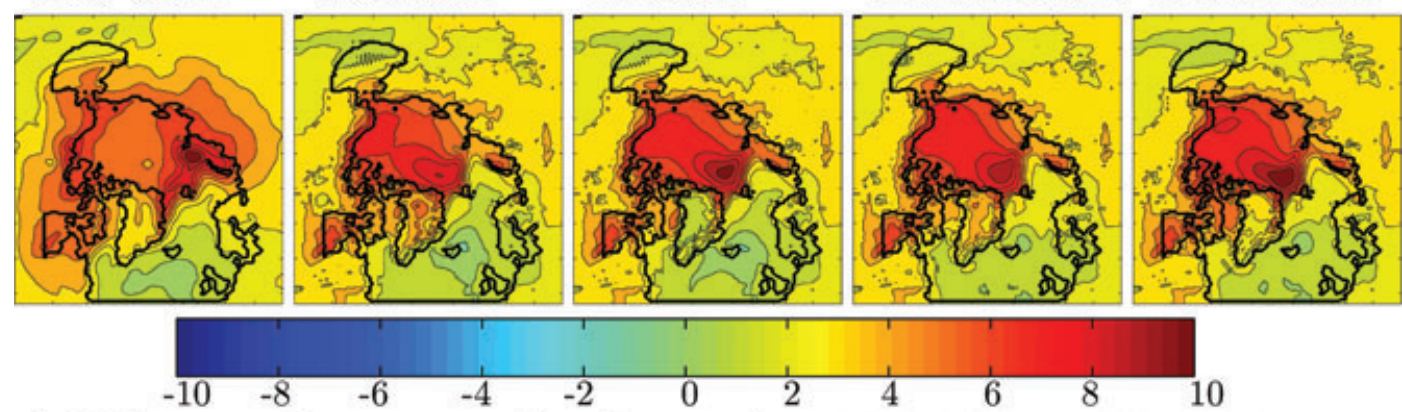

c) Differences between regional scenarios, 2060-2080 - 1980-2000

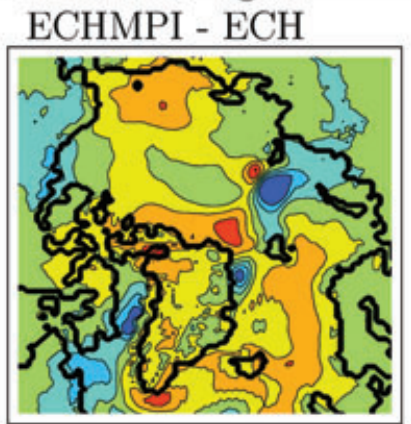

flux - stand
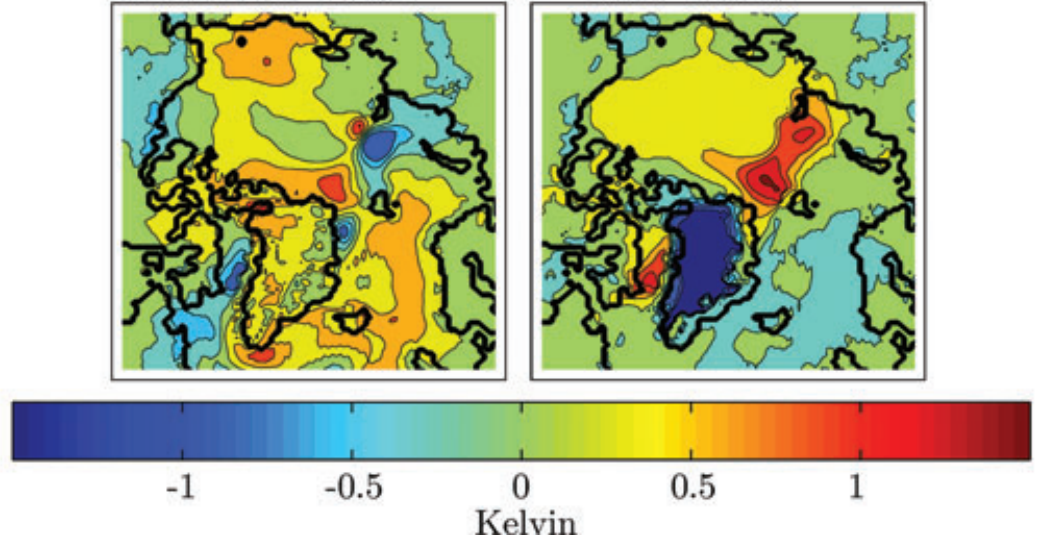

Fig. 8. Annual mean $2 \mathrm{~m}$ air temperature changes in Kelvin in the Arctic between (a) 2020-2040 and 1980-2000 and (b) $2060-2080$ and 1980-2000 in the global and regional ECH-simulations. (c) Differences between the mean of the fully forced runs (ECHMPIstand, ECHMPIflux) and the mean of the runs using ocean climatology (ECHstand, ECHflux) (left-hand panel) and the mean of the runs with salinity flux correction and (ECHflux, ECHMPIflux) and the mean of runs with salinity restoring (ECHstand, ECHMPIstand) (right-hand panel).

with an uncoupled regional atmosphere model and found warming rates between 2 and $3 \mathrm{~K}$ in summer and up to $8 \mathrm{~K}$ in winter for the period 2040-2060. This is comparable to the values we found in the Barents Sea region in this study.

The response over the Arctic land regions is somewhat larger in ECH_GCM than in the regional runs where the warming is more focussed on the Arctic Ocean itself. The reasons for the different warming rates over land are not fully clear. A generally thinner snow cover on land in the regional simulations might indicate a smaller potential for land warming.

Figure 8c shows the impact of using the full GCM-forcing and of using salinity flux correction instead of restoring. The full GCM-forcing leads to increased warming in most regions of the Nordic Seas and the Arctic Ocean. This is probably due to increased ocean heat input at the lateral boundaries into the North Atlantic. North of Kara Sea and in parts of Davis Strait 
and Labrador Sea, the temperature increase until 2060-2080 is reduced. The regional simulations with salinity flux corrections show an increased warming of more than $1^{\circ}$ north of Fram Strait, Barents Sea and Kara Sea probably due to stronger sea ice reductions compared to the simulations with salinity restoring. Also in Davis Strait an increased warming can be seen. Over Greenland, the temperature increase is strongly reduced for unknown reasons.

The loss of sea ice in the Arctic strongly increases the ocean heat release to the atmosphere. This can affect the local SLP as shown by Bengtsson et al. (2004) and Koenigk et al. (2009) for the Barents Sea. Additionally, it has an impact on the atmospheric baroclinity and has thus the potential to modulate the large-scale atmospheric circulation as shown, e.g. by Magnusdottir et al. (2004) or Alexander et al. (2004).

SLP is reduced in both BCM_GCM and ECH_GCM by about 0.5-1.5 hPa in most of the Arctic regions until 2020-2040.

The SLP response in BCMstand and ECHstand is similar compared to their corresponding GCMs (Fig. 9). There are some differences in the patterns, which are not significant and mainly due to internal variance in the regional simulations. BCMflux and ECHflux, which use a surface salinity flux correction instead of a less flexible relaxation to observed values, respond more sensitively and show particularly in the Barents Sea or further northwards a significantly stronger negative signal. Although if we take into account that a part of this response is due to internally generated variability, the fact that both the ECHand BCM-forced runs show a significant effect indicates a role of the increased degree of freedom of sea surface salinity. The changes in sea ice concentration clearly indicate a stronger reduction in the flux-runs, leading to more ocean-to-atmosphere heat release and thus reduced SLP. The surface salinity changes in ECHflux and BCMflux in the Barents Sea region are higher than in ECHstand and BCMstand. One possible explanation is that this leads to more mixing of warmer Atlantic water from below into the cold surface layer in winter and more sea ice melting or rather less sea ice formation.

The response in 2060-2080 is more pronounced in ECH_GCM than in BCM_GCM and reaches between -1.5 and $-3 \mathrm{hPa}$ in most of the Arctic, which agrees well with results of Chapman and Walsh (2007) who analysed the SLP change in 14 IPCC AR4 models. The larger SLP reduction in ECH_GCM compared to BCM_GCM can be attributed to the more extensive sea ice reduction in ECH_GCM. Consequently, vertical heat fluxes in the Arctic increase more and thus the SLP is further reduced. The SLP-response in both the regional BCM and ECHruns compare well to their respective GCM-run. Obviously, the response in the GCM is dominating the response in the regional simulations. In contrast to the response in 2020-2040, the flux runs do not any longer show a significantly larger change signal north of Barents Sea than the standard runs. This is caused by an ice-free Barents Sea in all runs, which leads to similar heat fluxes in all simulations. The adjacent regions do not seem to be as vulnerable to the salinity representation and thus no different responses appear there.

\subsection{Changes in variability}

3.2.1. Atmospheric circulation. The North Atlantic Oscillation (NAO, Hurrell, 1995) is one of the dominant large scale atmospheric circulation patterns in high northern latitudes. Figure 10 shows 10-yr running means of the SLP-difference between the Azores and Iceland. For the regional simulations, the Azores SLP is taken from the global simulations. Generally, regional and corresponding global simulations are highly correlated. However, a substantial bias towards smaller SLPdifferences and towards higher differences occur in the ECH-and BCM-regional simulations, respectively. This means that the Icelandic Low is less pronounced in the regional ECH-simulations and more pronounced in the regional BCM-simulations compared to the respective global simulations. Although the variability is governed by the external forcing at the lateral boundaries, the mean value is similar in the regional ECH and BCMsimulations. The mean SLP-difference between Azores and Iceland in the ERA40-data is $18.4 \mathrm{hPa}$, which is slightly below ECH_GCM and slightly higher than in the regional simulations. However, the variations in the ERA-40 data are large between very low values $(10 \mathrm{hPa})$ in the 1960 s and 1970 s and very high values (up to $24 \mathrm{hPa}$ ) in the 1990s. Analyses of a reconstructed NAO time series from 1865 to 1997 by Jones et al. (1997) show that both the minimum in the 1960s and the maximum in the 1990 s are extreme values for the entire 130 -yr period. Nevertheless, none of the global or regional runs reproduce such large variations in the period 1960-2100.

All global and regional ECH and BCM-simulations show decadal to multi-decadal variations, which also appear in the reconstructed time series of Jones et al. (1997). The ECHsimulations show a very small negative trend in the SLP difference across the North Atlantic while the BCM-simulations indicate an increasing SLP-gradient in the future. In the BCMruns both Icelandic Low and Azores High become more intensive while SLP changes over Iceland and Azores are very small in the ECH-runs (Fig. 9).

Although the SLP-gradient between Azores and Iceland only shows a small trend during the 21 st century, the corresponding spatial correlation patterns between NAO and SLP differ strongly between 1980-2000, 2020-2040 and 2060-2080 (Fig. 11). The negative correlation of NAO and SLP around Iceland extends further into the Arctic Ocean in future. In 2060-2080, SLP in the entire Arctic Ocean is strongly negatively correlated with the NAO, which reflects a reduced SLP gradient across the Arctic. The correlation between NAO and air temperature shows in 1980-2000 a dipole pattern with significant colder temperatures from the Canadian Archipelago across Labrador Sea towards the northern North Atlantic and increased temperatures over the Nordic Seas and Scandinavia. Observational based 
a) Annual mean SLP change, 2020-2040 - 1980-2000

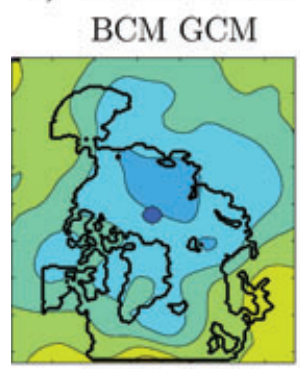

ECH GCM

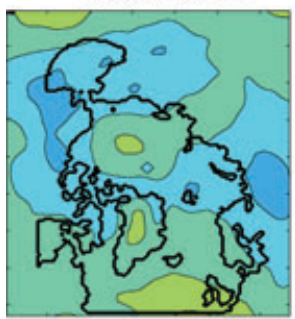

BCMstand

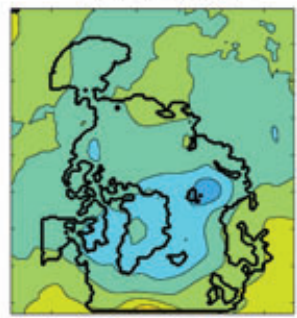

ECHstand

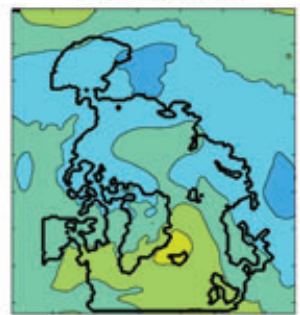

BCMflux

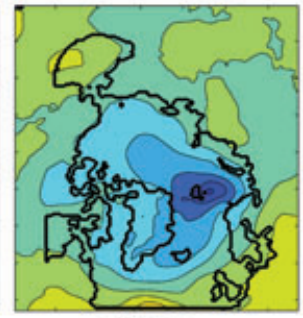

ECHflux

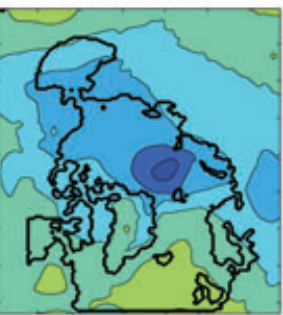

ECHMPIstand

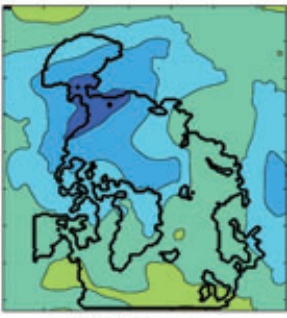

ECHMPIflux

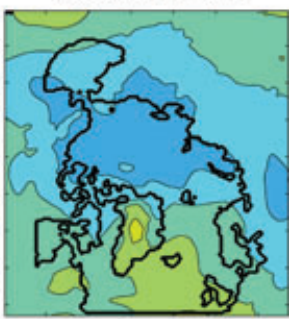

b) Annual mean SLP change, 2060-2080 - 1980-2000 BCM GCM

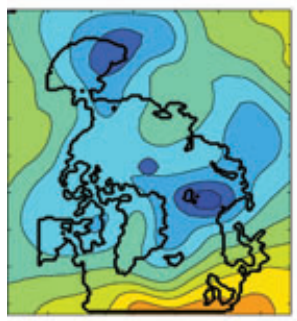
BCMstand

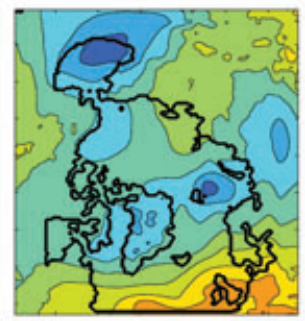
ECHstand
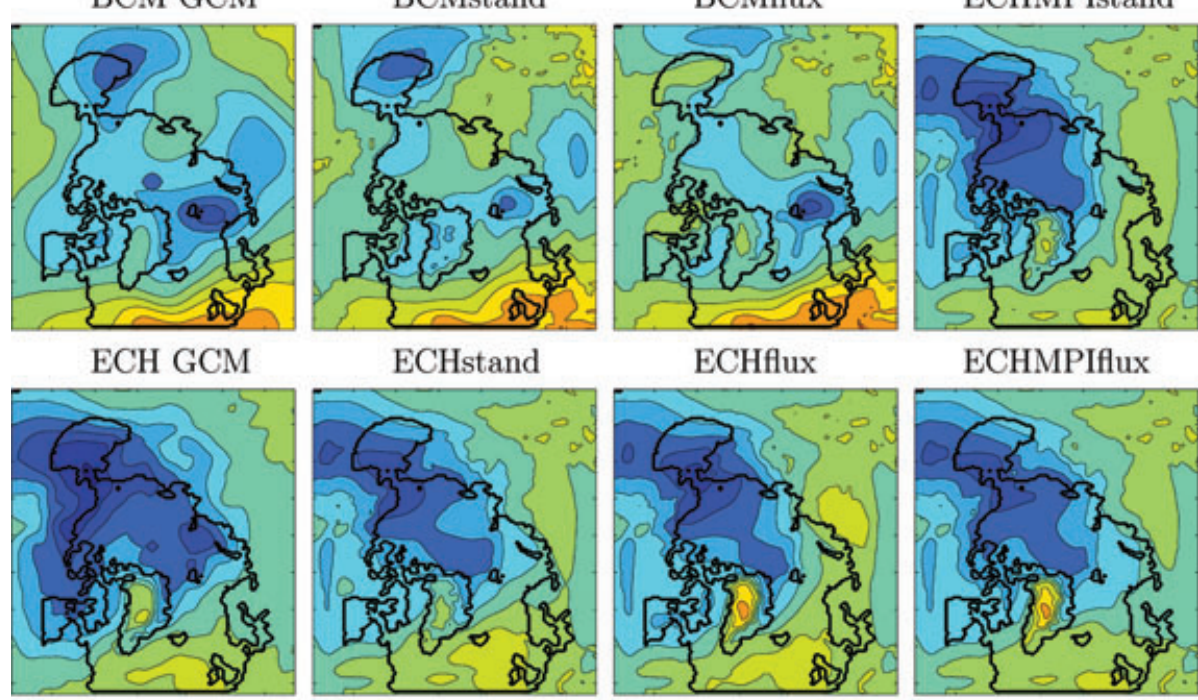

ECHflux

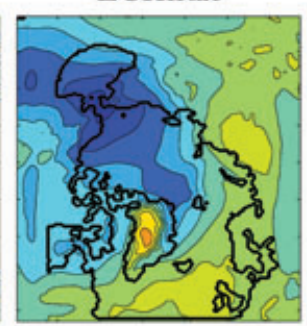

ECHMPIflux
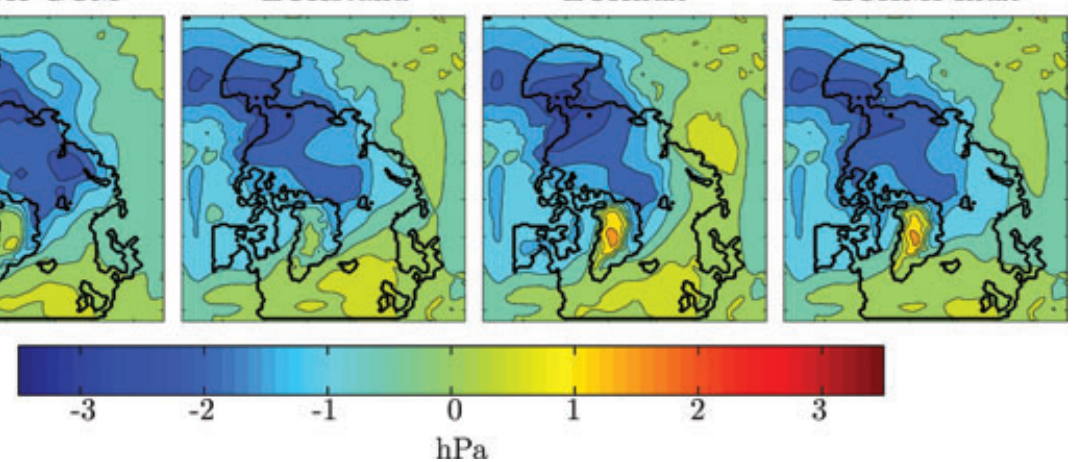

Fig. 9. Annual mean SLP changes in hPa between (a) 2020-2040 and 1980-2000 and (b) 2060-2080 and 1980-2000 in the global and regional ECH- and BCM-simulations.

correlation patterns between $\mathrm{NAO} / \mathrm{AO}$ and air temperature (Hurrell, 1995; Graversen, 2006) also show a dipole but with a somewhat larger extension towards Siberia and a less pronounced negative pole. In our future simulations, the NAO shows an increasing effect on air temperature over Siberia.

The anomalous winds from the Atlantic part to the Pacific part of the Arctic during a high NAO-winter become much weaker in the future periods. This leads to a smaller impact on sea ice variations in the Arctic. In 1980-2000, sea ice thickness is significantly correlated with the NAO and shows clearly a dipole pattern with thicker ice in the Pacific Arctic and negative anomalies in the Atlantic part of the Arctic during a positive NAO. In the future periods, the pattern is still observable but the correlations are much smaller and not longer significant. These changes are more pronounced in the regional ECH-simulations than in ECH_GCM and probably connected to the stronger retreat of sea ice and thinner ice in the ECHdownscalings. 


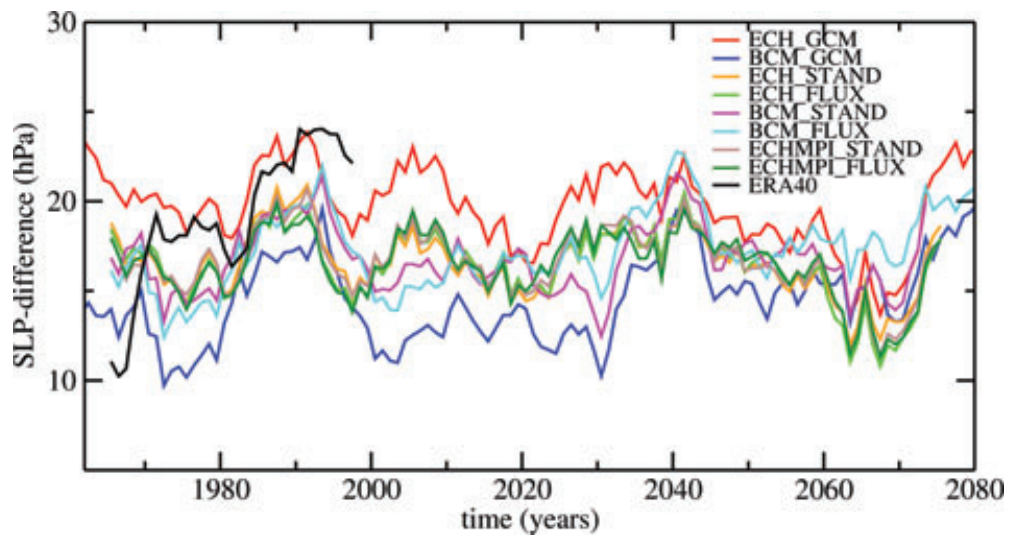

Fig. 10. Ten-year running mean of DJF SLP-difference in $\mathrm{hPa}$ between Azores and Iceland in the global and regional simulations.
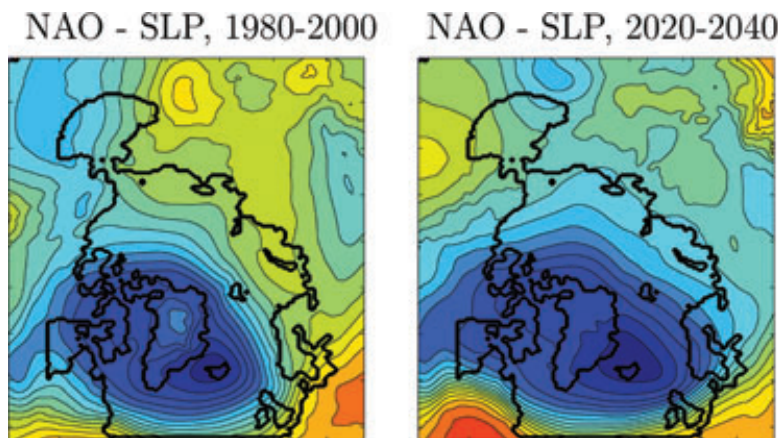

NAO - SLP, 2060-2080
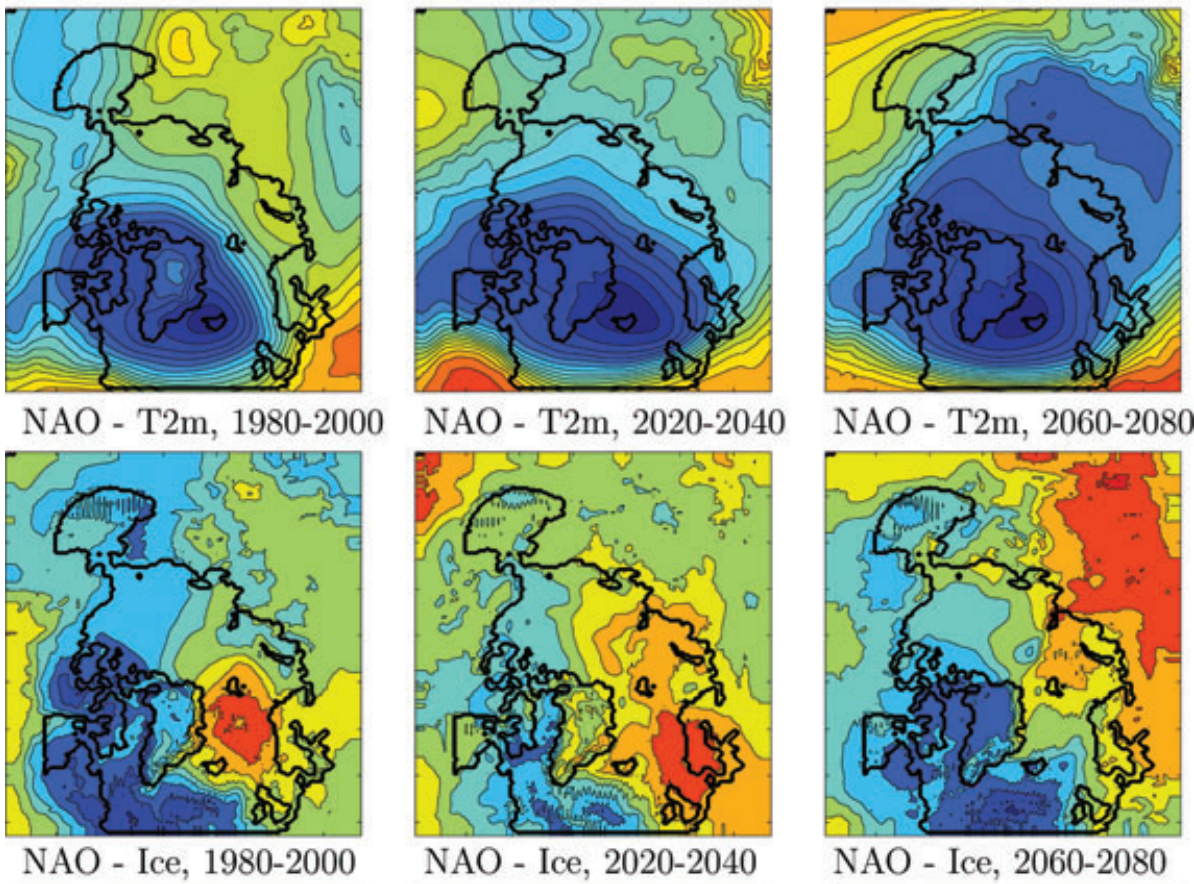

NAO - T2m, 2060-2080
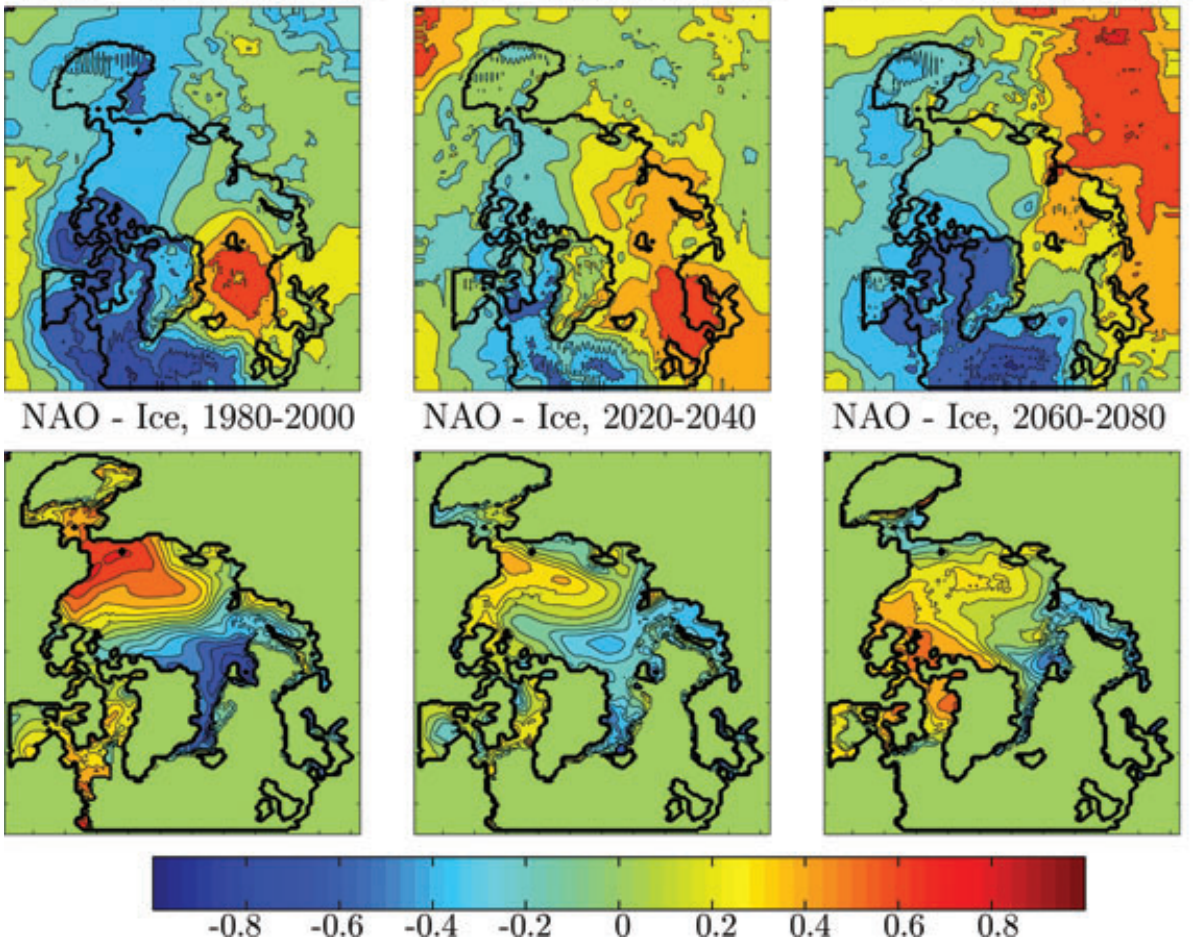

Fig. 11. Correlation between winter NAO and annual mean SLP (top panel), annual mean $2 \mathrm{~m}$ air temperature (T2m, middle panel) and annual mean sea ice thickness (bottom panel) in the periods 1980-2000 and 2060-2080 in ECHstand. 
SLP DJF, stddev, 1980-2000
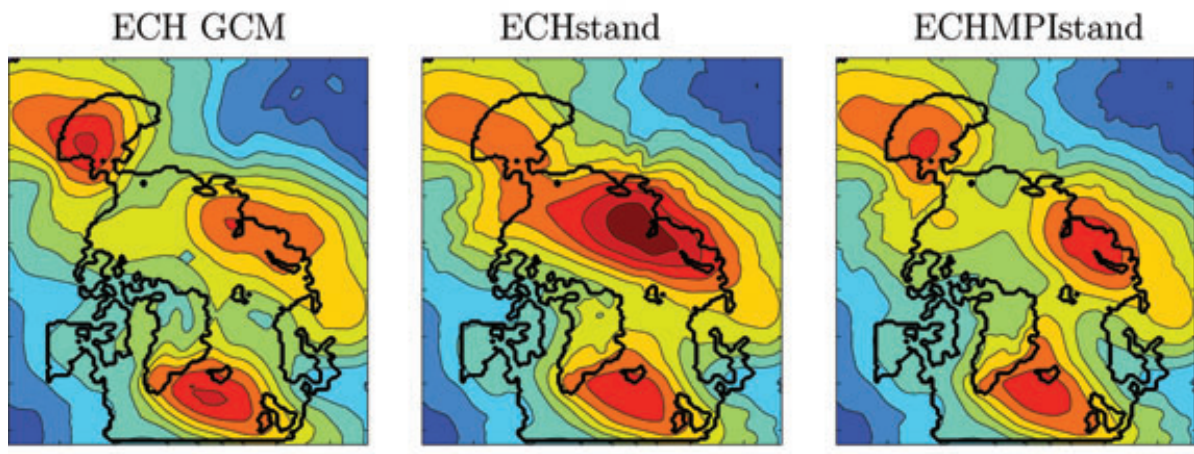

SLP DJF, stddev, 2060-2080
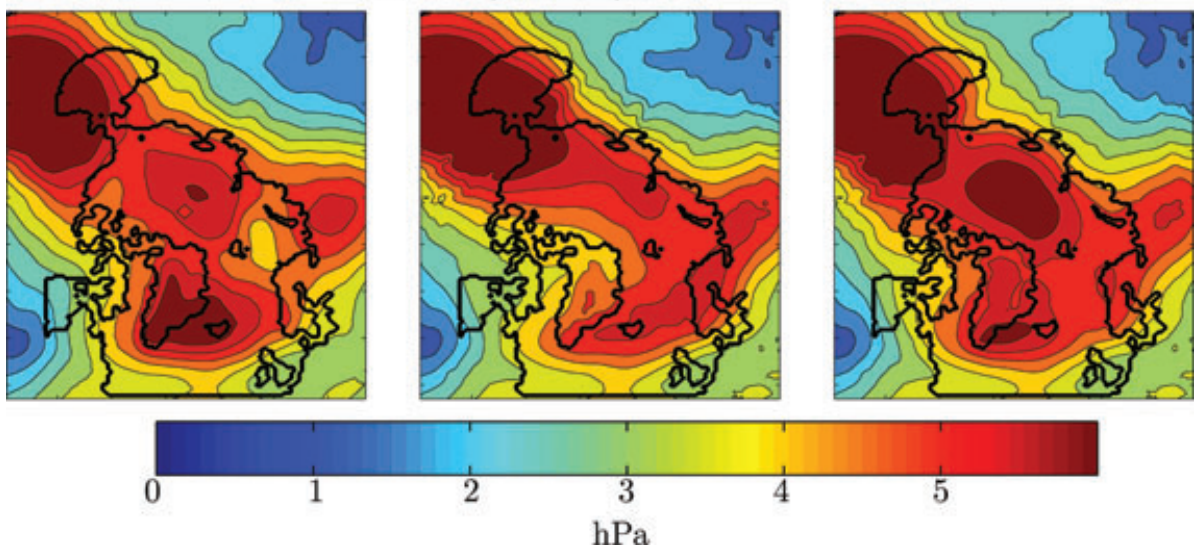

Fig. 12. Standard deviation in hPa of winter mean (DJF) SLP in ECH_GCM, ECHstand and ECHMPIstand in 1980-2000 and 2060-2080.

Not only the correlation pattern between NAO-index and SLP but also the variability of Arctic SLP changes substantially (Fig. 12). The standard deviation of winter mean SLP in both the regional and the global ECH-simulations increase strongly over most of the Arctic Ocean, the North Pacific and western North America until 2060-2080. In the period 1980-2000, maxima in the Arctic occur over Iceland, the Siberian coast and the Bering Sea. In 2060-2080, these maxima are still apparent but are partly merging since variability of SLP in the entire Arctic Ocean area is high. The maximum at the Siberian coast moves towards the centre of the Arctic. This and the strong increase of variability in most of the Arctic Ocean area can probably be attributed to the loss of sea ice, which might allow for more cyclonic activity in the Arctic. Generally, the pattern of ECH_GCM and ECHMPIstand compare somewhat better than those of ECH_GCM and ECHstand, indicating local influences of additional heat transport into the Arctic on the SLP variability.

3.2.2. Daily extremes. Changes in mean conditions and interannual variability in the Arctic do not represent the entire Arctic climate change. To get a more complete picture of the climate change, daily extremes are analysed. Figure 13 show the change of SLP for the 5\% winter and summer days with lowest and highest SLP between 2060-2080 and 1980-2000 for the ECHstand simulation. The 5\% winter days with lowest SLP show a decrease of 4-10 hPa in most of the Arctic Ocean. The strongest reduction occurs over the Bering Strait. One possible explanation is that reduced sea ice cover leads to more cyclonic activity in this region and hence more pronounced minima in the Arctic. Also the warmer climate might contribute to stronger storms by sending more water vapour in the region, facilitating more baroclinicity. The 5\% days with highest SLP (Fig. 13, bottom) only show comparatively small changes. Even in 2060-2080, periods occur with a Siberian High extending over the Arctic Ocean and leading to similar maximum SLP values as in the control period. This means that the probability density function (PDF) of daily winter SLP widens at the lower end. This fits well to the increase in standard deviation of SLP over the Arctic (Fig. 12), which might be related to an increase of cyclones in the Arctic. Such possible future development would continue an observed trend. Already in the second half of the 20th century, a significant increase of both frequency and intensity of cyclones in high northern latitudes occur as McCabe et al. (2001) showed by analysing storm tracks in the NCEP-NCAR reanalysis data from 1959 to 1997.

During summer, a more heterogeneous change pattern for the $5 \%$ days with lowest SLP is found. Over the Siberian side of the Arctic and over northwestern Europe, the low pressure extremes increase with a few $\mathrm{hPa}$ while extremes are more pronounced 
Changes in daily SLP extremes, 2060-2080 - 1980-2000

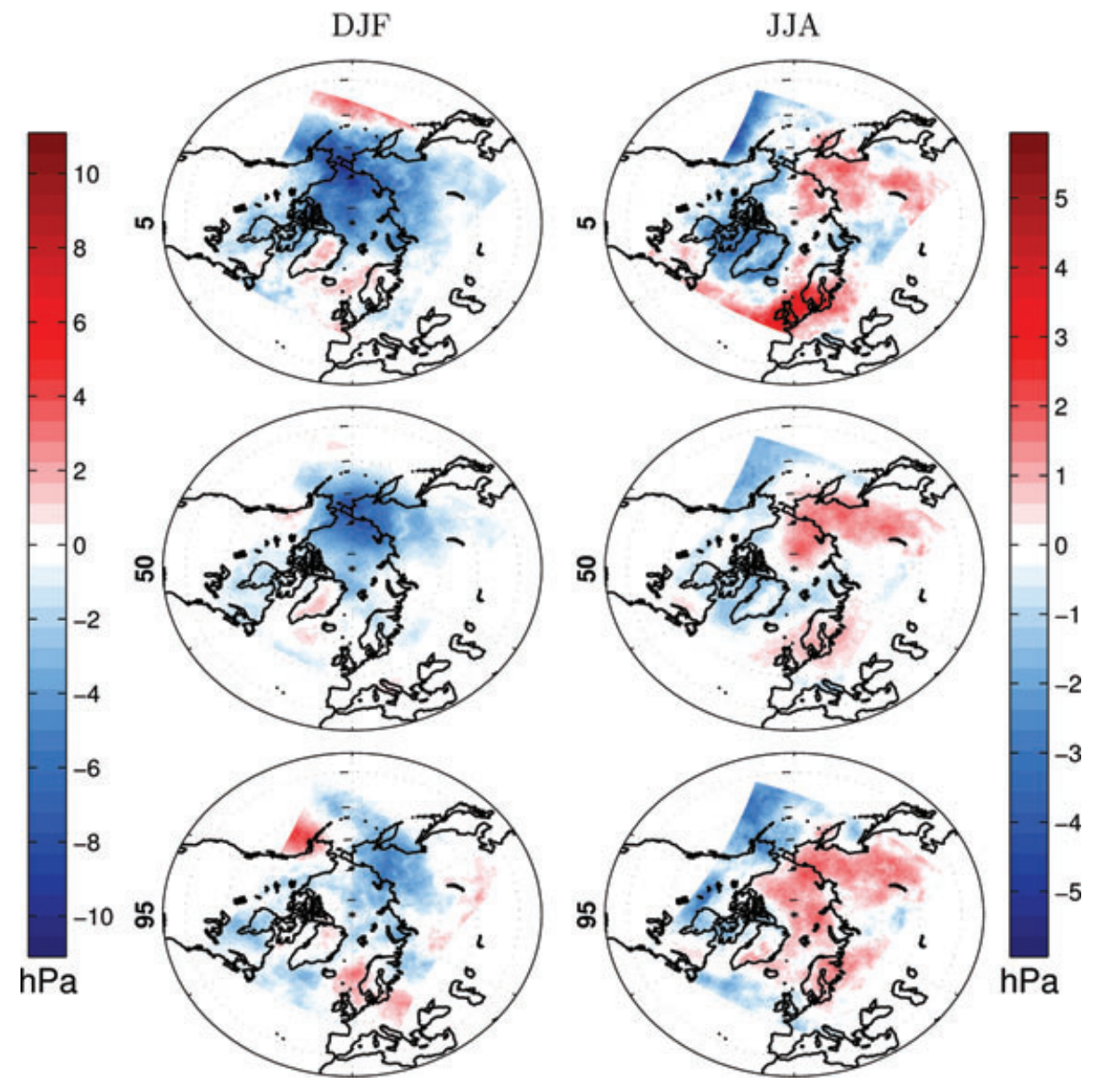

Fig. 13. Changes in daily extremes of SLP between 2060-2080 and 1980-2000 in ECHstand in winter and summer: Top panel: SLP change of the $5 \%$ days with lowest SLP, middle: mean change. Bottom panel: SLP change of the 5\% days with highest SLP.

from Greenland over North America to the North Pacific. The change pattern is similar for high-pressure extremes. This means that a shift of the PDF towards higher values occur over the Siberian part and towards lower values over the North American part but the shape of the PDF remains the same. Over northwestern Europe we see only a small increase for the 5\% days with highest SLP, which leads to a tighter PDF of SLP in this region.

Also the PDF of $2 \mathrm{~m}$ air temperature does not only shift towards warmer values in future. In winter, a general warming occurs for both cold and warm extremes (Fig. 14). However, strongest warming of cold days is found along the displaced ice edges while the warm days show maximum warming in the centre of the Arctic. Over the North Atlantic both warm and cold extremes remain almost unchanged.

In summer, the cold extremes remain almost unchanged over the Arctic Ocean. The surface temperature is a lower limit for the air temperature over the oceans. Although the Arctic Ocean is almost ice free during summers 2060-2080, the ocean SST is still near freezing temperature and cold extremes are hence very sim- ilar in 1980-2000 and 2060-2080. In contrast, the warm summer extremes over the Arctic Ocean show a substantial warming of several degrees. This is probably due to a combination of warm air advection from the continents and a beginning warming of the ocean especially along the North American coast where winter sea ice disappears rather early in the year in 2060-2080. Over the land areas, a comparable temperature increase occur for both cold and warm days.

Kharin et al. (2007) analyzed the changes in daily maximum and minimum $2 \mathrm{~m}$ air temperature with 20 -yr return period between 1981-2000 and 2046-2065 in the IPCC-AR4 simulations. Similar to our study, they found a stronger warming of the coldest days ( 4 to more than $10 \mathrm{~K}$ ) than of the warmest days (2-4 K) in the Arctic. In comparison, our simulations show a warming of $5-20 \mathrm{~K}$ of the $5 \%$ coldest days in winter and $2-8 \mathrm{~K}$ of the warmest days in summer.

Rinke and Dethloff (2008) used an Arctic regional atmospheric model to downscale A1B scenarios of ECHAM5/MPIOM for the time-slices 1980-1999, 2046-2065 and 2080-2099. 
Changes in daily $2 \mathrm{~m}$ air temperature extremes, 2060-2080 - 1980-2000
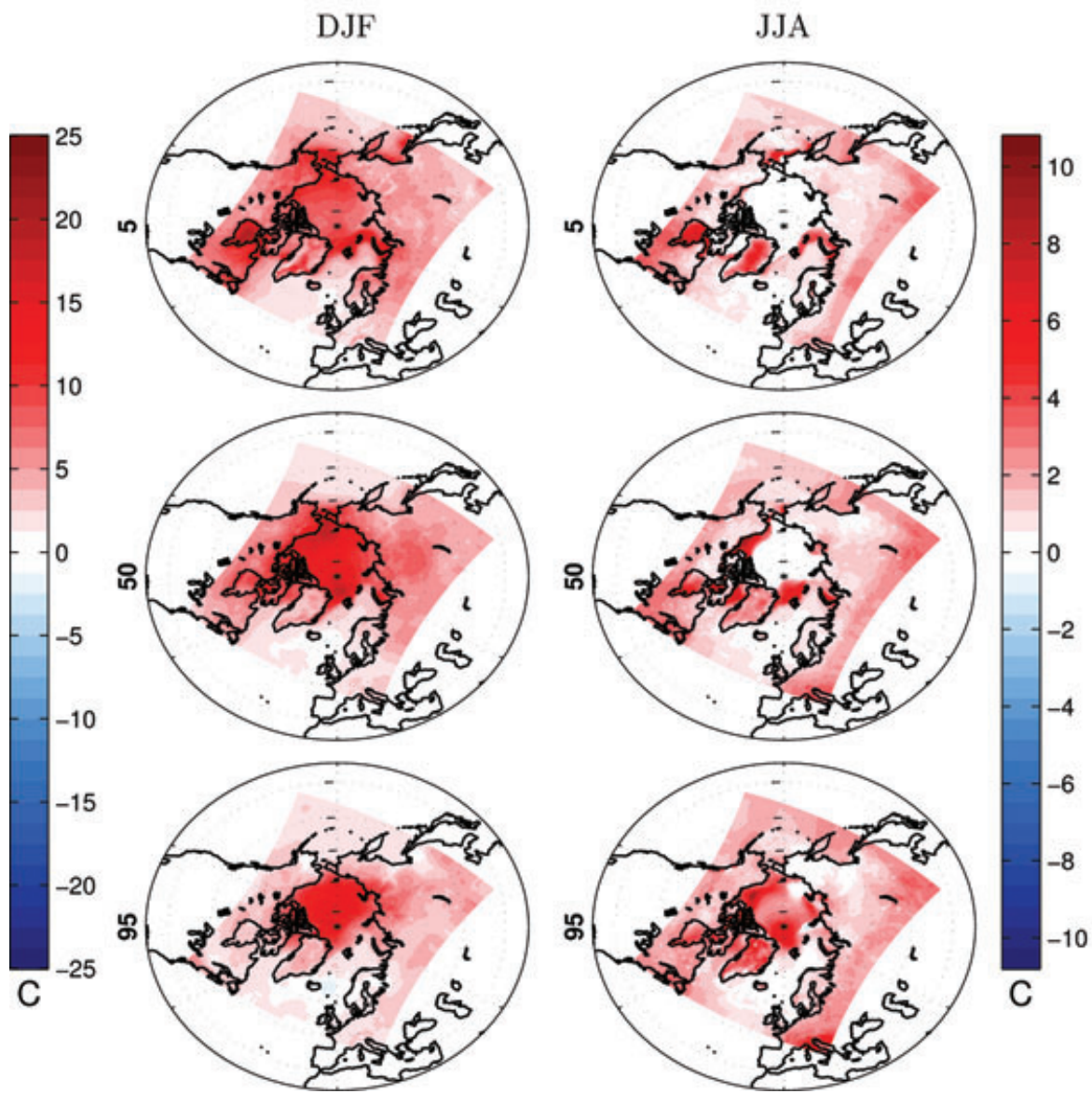

Fig. 14. Changes in daily extremes of $2 \mathrm{~m}$ air temperature between 2060-2080 and 1980-2000 in ECHstand in winter and summer: Top panel: temperature change of the $5 \%$ coldest days, middle: mean change. Bottom panel: temperature change of the $5 \%$ warmest days.

Their daily winter extremes of temperature show a similar change in the 21 st century both in amplitude and pattern. However, the change for summer temperature extremes seems to differ. Even if the results are not completely comparable because Rinke and Dethloff (2008) analysed the change of daily minimum and maximum temperature while we analysed the change of coldest and warmest daily mean temperature, our results indicate an increasing temperature range between cold and warm extremes while their results mean a shrunken temperature range in summer. Their change pattern for maximum summer temperatures is very similar to our change pattern of cold extremes over the Arctic Ocean during future summers. This is probably due to the fact that ECHAM5/MPI-OM (used by Rinke and Dethloff (2008) as surface boundary conditions) has much more sea ice left than our regional coupled downscaling of ECHAM5/MPI-OM. The related colder surface used by Rinke and Dethloff prevents temperatures much above freezing level. The mean summer and winter $2 \mathrm{~m}$ air temperature change patterns compare well between their and our study but the regions with strongest warming are shifted slightly into the
Arctic in our study, probably due to less sea ice. In contrast, SLP change pattern are different particularly during summer time where Rinke and Dethloff show a substantial reduction of SLP in the Nordic Seas and over Greenland while our study indicates no strong changes in this region. Again, this different behaviour might be related to the different sea ice distribution and the possibility for coupled ocean-sea ice-atmosphere feedbacks in our coupled regional model.

\section{Summary and conclusions}

This study analyses possible Arctic climate changes by downscaling the global climate models ECHAM5/MPI-OM and BCCR2.0 with the regional coupled climate model RCAO. Six different regional experiments are performed, which use different parts of the GCM forcing at the lateral boundaries: either both oceanic and atmospheric forcing or only atmospheric GCM forcing and an ocean climatology. Two different ways in the treatment of the surface salinity are used: restoring towards 20th century climatology or salinity flux correction. 
Analyses of Arctic air temperature and sea ice cover show that the regional simulations forced with ECHAM5/MPI-OM agree best with ERA-40 reanalysis data during the control period 1980-2000. Both the ECHAM- and BCM-forced regional simulations are warmer than their corresponding global runs, which are both colder than ERA-40. Thus, the regional runs compare better to the ERA-40 data during the control period compared to the global simulations. The warming trend is particularly over land slightly smaller in the regional simulations.

The response of Arctic sea ice cover in the regional runs compared to the global simulations is seemingly not consistent. Although both global ECHAM and BCM model simulate too much ice in the Arctic only the ECHAM-forced but not the $\mathrm{BCM}$-forced regional simulations show a reduction compared to the global run. The boundary conditions given by the GCM set the stage for Arctic climate behaviour, but the regional models sea ice extent responds in a non-linear way. Furthermore, in both the regional and global ECHAM-simulations a strong negative sea ice cover trend occur while the trend is rather small in the BCM-simulations.

The regional ECHAM-forced runs show strong decadal variations with rapid sea ice reduction periods and partly recovery to the multiannual trend thereafter. Such events compare well to the recently observed sea ice reduction and might indicate that also real-world Arctic sea ice cover can recover to the longterm trend. The increasing observed sea ice extents in summers 2008 and 2009 compared to the 2007 minimum could be part of such a recovery. Our simulations suggest a first almost (below $1 \times 10^{6} \mathrm{~km}^{2}$ ) total summer sea ice loss around 2040 and no substantial recovery after 2060 any longer.

Large-scale changes in the spatial patterns of the downscaling runs depend strongly, but not exclusively, on the forcing GCM. The large-scale atmospheric change pattern in the regional runs is very similar to that of the corresponding GCM and show reduced SLP in most of the Arctic with strongest reductions in regions where sea ice is particularly reduced. Locally, significant differences occur between the global and regional simulations. Such a region is the Barents Sea where the regional runs show the tendency of a local amplification. The same is true for the temperature change: the large-scale pattern is governed by the GCM but significant differences occur. Most of these differing responses are related to differences in the sea ice simulations, which are probably mainly due to different adjustments of the ice parameters in ECHAM5/MPI-OM, BCCR2.0 and RCAO. The ECHAM-forced regional simulations show a larger reduction in sea ice cover than the global ECHAM5/MPI-OM, which leads to a stronger and faster warming in the Arctic Ocean region in the regional runs.

The NAO-index in the ECHAM-simulations is largely varying within the observational range of recent climate, but the impact of the NAO on SLP and sea ice in the Arctic is strongly changing. The negative correlation of the NAO with SLP extends more and more into the Arctic Ocean and to Siberia, which is connected with a weaker SLP gradient across the Arctic. Consequently, anomalous winds in the Arctic during high NAO-phases are reduced and the impact of the NAO on sea ice is reduced.

The deviations in the response between the regional simulations corresponding to the same global model are small. Using ocean GCM forcing at the lateral domain boundaries compared to climatology leads to a moderate warming of the Arctic Ocean in the order of some tenth of a degree and a slightly enhanced sea ice melting. Most of the additional heat input into the ocean is lost to the atmosphere or distributed in deeper layers before it can affect the ice-covered Arctic Ocean.

The regional simulations using salinity flux correction instead of salinity restoring show particularly in the nearer future (2020-2040) a tendency to an amplification of the response. This signal is most pronounced in the Barents Sea and occurs both in the BCM- and ECHAM-forced simulations. A faster reduction of sea ice in the Barents Sea leads to enhanced ocean to atmosphere heat fluxes and locally reduced SLP. As a consequence, anomalous winds transport more sea ice to the south in winter time and lead to a temperature reduction in the Greenland Sea in 2020-2040 compared to 1980-2000.

This study demonstrated the importance of coupled regional downscaling of global climate scenarios in the Arctic. The regional coupled model with its better resolution and representation of local conditions and processes, and with the possibility to carry out multiple runs under varying conditions, helps to an advanced understanding of underlying uncertainties and mechanisms. In addition, the more realistic recent climate representation compared to the global models tends to give us more confidence for the future simulations although it has not been proven that the model with the best representation of present-day climate will provide the best future simulations.

Despite the additional value provided by the regional downscaling, this study clearly indicates the importance of the global forcing for the regional results. The best regional model will not provide realistic results if the large scale forcing at the lateral boundaries is unrealistic. Thus, further improvement of the physics and increase in resolution of both regional and global models are necessary to further understand and minimize the uncertainties in Arctic future climate simulations.

\section{Acknowledgments}

This study has been made possible by support of the Rossby Centre at the Swedish Meteorological and Hydrological Institute (SMHI) together with the EU project DAMOCLES. The DAMOCLES project is financed by the European Union in the 6th Framework Programme for Research and Development. We are especially grateful for the long-term development effort by the Rossby Centre/SMHI staff, invested into the regional models RCA and RCO, which form the base for RCAO. We also thank Ingo Bethke (NERSC) and the Max-Planck Institute for 
Meteorology for provision of GCM data, and Ulf Hansson and Anders Ullerstig for preparation of the lateral forcing.

\section{References}

Alexander, M., Bhatt, U., Walsh, J., Timlin, M., Miller, J. and co-authors. 2004. The atmospheric response to realistic Arctic sea ice anomalies in an AGCM during winter. J. Clim. 17, 890-905.

Bengtsson, L., Semenov, V..A. and Johannessen, O. M. 2004. The early twentieth-century warming in the arctic-a possible mechanism. $J$. Clim. 17, 4045-4057.

Cavalieri, D., Parkinson, C., Gloersen, P. and Zwally, H.J. 1996, updated 2008. Sea Ice Concentrations from Nimbus-7 SMMR and DMSP SSM/I Passive Microwave Data. National Snow and Ice Data Center. Digital media, Boulder, Colorado, USA.

Chapman, W. L. and Walsh, J. E. 2007. Simulations of Arctic temperature and pressure by global coupled models. J. Clim. 20, 609632.

Comiso, J. C., Parkinson, C. L., Gersten, R. and Stock, L. 2008. Accelerated decline in the Arctic sea ice cover. Geophys. Res. Lett. 35 , L01703, doi:10.1029/2007GL031972.

Deser, C., Magnusdottir, G. Saravan, R. and Philips, A. 2004. The effects of North Atlantic SST and sea ice anomalies on the winter circulation in CCM3. Part II: direct and indirect components of the response. $J$. Clim. 17, 2160-2176.

Divine, D. D. and Dick, C. 2006. Historical variability of the sea ice edge position in the Nordic Seas. J. Geophys. Res. 111, C01001, doi:10.1029/2004JC002851.

Dorn, W., Dethloff, K., Rinke, A., Frickenhaus, S., Gerdes, R. and coauthors. 2007. Sensitivities and uncertainties in a coupled regional atmosphere-ocean-ice model with respect to the simulation of Arctic sea ice. J. Geophys. Res. 112, D10118, doi:10.1029/2006JD007814.

Dorn, W., Dethloff, K., Rinke, A. and Kurgansky, M. 2008. The recent decline of the Arctic summer sea-ice cover in the context of internal climate variability. Open Atmos. Sci. J. 2, 91-100.

Döscher, R., Willén, U., Jones, C., Rutgersson, A., Meier, H. E. M. and co-authors. 2002. The development of the coupled ocean-atmosphere model RCAO. Boreal Environ. Res. 7, 183-192.

Döscher, R., Wyser, K., Meier, H. E. M., Qian, M. and Redler, R. 2010. Quantifying Arctic contributions to climate predictability in a regional coupled ocean-ice-atmosphere model. Clim. Dyn. 34, 7-8, doi:10.1007/s00382-009-0567-y.

Gerdes, R. and Köberle, C. 2007. Comparison of Arctic sea ice thickness variability in IPCC Climate of the 20th Century experiments and in ocean-sea ice hindcasts. J. Geophys. Res. 112, C04S13, doi:10.1029/2006JC003616.

Goosse, H., Selten, F., Haarsma, R. and Opsteegh, J. 2002. A mechanism of decadal variability of the sea-ice volume in the Northern Hemisphere. Clim. Dyn. 19, 61-83, doi:10.1007/s00382-001-0209-5.

Graversen, R.G. 2006. Do changes in the midlatitude circulation have any impact on the Arctic surface air temperature trend? J. Clim. 19, 5422-5436.

Hilmer, M. and Lemke, P. 2000. On the deacrease of arctic sea ice volume. Geophys. Res. Lett. 27(7), 989-992.

Holland, M. M., Bitz, C. M. and Tremblay, B. 2006. Future abrupt reductions in the Summer Arctic sea ice. Geophys. Res. Lett. 33, L23503, doi:10.1029/2006GL028024.
Hunke, E. C. and Dukowicz, J. K. 1997. An elastic-viscous-plastic model for sea ice dynamics. J. Phys. Oceanogr. 27, 1849-1867.

Hurrell, J. 1995. Decadal trends in the North Atlantic Oscillation: regional temperatures and precipitation. Science 269, 676-679.

Jones, C. G., Willén, U., Ullerstig, A. and Hanson, U. 2004a. The Rossby Centre Regional Atmospheric Climate Model part I: model climatology and performance for the present climate over Europe. Ambio. 33(4/5), 199-210

Jones, C. G., Wyser, K., Ullerstig, A. and Willén, U. 2004b. The Rossby Centre Regional Atmospheric Climate Model part II: application to the Arctic climate. Ambio. 33(4/5), 211-220.

Jones, P. D., Jonsson, T. and Wheeler, D. 1997. Extension to the North Atlantic Oscillation using early instrumental observations from Gibraltar and south-west Iceland. Int. J. Climatol. 17, 14331450

Jungclaus, J. H. and Koenigk, T. 2009. Low-frequency variability of the arctic climate: the role of the oceanic and atmospheric heat transport variations. Clim. Dyn. 34, published online, doi:10.1007/s00382-0090569-9.

Keup-Thiel, E., Göttel, H. and Jacob, D 2006. Regional climate simulations for the Barents Sea region. Boreal Environ. Res. 11, 329 339.

Kharin, V. V., Zwiers, F. W., Zhang, X. and Hegerl, G. C. 2007. Changes in temperature and precipitation extremes in the IPCC ensemble of global coupled model simulations. J. Clim. 20, doi:10.1175/JCLI4066.1.

Kjellström, E., Bärring, L., Gollvik, S., Hansson, U., Jones, C. and coauthors. 2005. A 140-year simulation of the European climate with the new version of the Rossby Centre regional atmospheric climate model (RCA3). SMHI reports meteorology and climatology RMK No. 108, 54.

Koenigk, T., Mikolajewicz, U., Haak, H. and Jungclaus, J. 2006. Variability of Fram Strait sea ice export: causes, impacts and feedbacks in a coupled climate model. Clim. Dyn. 26, 17-34, doi:10.1007/s00382005-0060-1.

Koenigk, T., Mikolajewicz, U., Jungclaus, J. and Kroll, A. 2009. Sea ice in the Barents Sea: seasonal to interannual variability and climate feedbacks in a global coupled model. Clim. Dyn. 32, 1119-1138, doi:10.1007/s00382-008-0450-2.

Koltzow, M. 2007. The effect of a new snow and sea ice albedo scheme on regional climate model simulations. J. Geophys. Res. 112, D07110, doi:10.1029/2006JD007693.

Magnusdottir, G., Deser, C. and Saravanan, R. 2004. The effects of North Atlantic SST and Sea Ice Anomalies on the winter circulation in CCM3. Part I: main features and storm track characteristics of the response. J. Clim. 17(5), 857-876.

Maslowski, W., Marble, D., Walczowski, W., Schauer, U., Clement, J. L. and co-authors. 2004. On climatological mass, heat, and salt transports through the Barents Sea and Fram Strait from a pan-Arctic coupled ice-ocean model simulation. J. Geophys. Res. 109, C03032, doi:10.1029/2001JC001039.

McCabe, G. J., Clark, M. P. and Serreze, M. C. 2001. Trends in Northern Hemisphere surface cyclone frequency and intensity. J. Clim. 14, 2763-2768.

Meier, H. E. M., Döscher, R. and Faxén, T. 2003. A multiprocessor coupled ice-ocean model for the Baltic Sea: application to salt inflow. J. Geophys. Res. 108(C8), 3273, doi:10.1029/2000JC000521. 
Mikolajewicz ,U., Sein, D. V., Jacob, D., Königk, T., Podzun, R. and co-authors. 2005. Simulating Arctic sea ice variability with a coupled regional atmosphere-ocean-sea ice model. Meteorol.ogische Zeitschrift 14(6), 793-800.

Parkinson, C. L., Cavalieri, D. J., Gloersen, P., Zwally, H. J. and Comiso J. C. 1999. Arctic sea ice extents, areas and trends, 1978-1996. J. Geophys. Res. 104(C9), 20837-20856.

Perovich, D. K., Richter-Menge, J. A., Jones, K. F. and Light, B. 2008. Sunlight, water, and ice: extreme Arctic sea ice melt during the summer of 2007. Geophys. Res. Lett. 35(L11501), doi:10.1029/2008GL034007.

Polyakov, I., Bekryaev, R. V., Alekseev, G. V., Bhatt, U.S., Colony, R. L. and co-authors. 2003. Variability and trends of air temperature and pressure in the maritime Arctic, 1875-2000. J. Clim. 16(12), 2067-2077.

Rinke, A., Maslowski, W., Dethloff, K. and Clement, J. 2006. Influence of sea ice on the atmosphere: a study with an Arctic atmospheric regional climate model. J. geophys. Res. 111, D16103, doi:10.1029/2005JD006957.

Rinke, A. and Dethloff, K. 2008. Simulated circum-Arctic climate changes by the end of the $21^{\text {st }}$ century. Global Planet. Change $\mathbf{6 2}$, 173-186, doi:10.1016/j,gloplacha.2008.01.004.

Rothrock, D. A., Zhang, J. and Yu, Y. 2003. The Arctic ice thickness anomaly of the 1990s: a consistent view from observations and models. J. Geophys. Res. 108(C3), 30-83, doi:10.1029/2001JC001208.
Samuelsson, P., Gollvik, S. and Ullerstieg, A. 2006. The land-surface scheme of the Rossby Centre regional atmospheric climate model (RCA3). Report in meteorology 122, SMHI. SE-60176, Norrköping, Sweden.

Semtner, A. J. 1976. A model for the thermodynamic growth of sea ice in numerical investigations of climate. J. Phys. Oceanogr. 6, 27-37.

Serreze, M. C., Walsh, J. E., Chapin III, F. S., Osterkamp, T., Dyurgerov, M. and co-authors. 2000. Observational eveidence of recent change in the northern latitude environment. Clim. Change 46, 159207.

Simmons, K. and Haugan, P. M. 1996. Heat budgets of the Arctic Mediterranean and sea surface heat flux parameterizations for the Nordic Seas. J. Geophys. Res. 101(C3), 6553-6576.

Steele, M., Morley, R. and Ermold, W. 2001. PHC: a global ocean hydrography with a high quality Arctic Ocean. J. Clim. 14, 2079-2087.

Stroeve, J., Holland, M., Meier, W., Scambos, T. and Serreze, M. 2007. Arctic sea ice decline: faster than forecast. Geophys. Res. Lett. 34, L09501, doi:10.1029/2007GL029703.

Valcke, S. and Redler, R. 2006. OASIS4 user.guide (OASIS4_0_2). PRISM support initiative report no. 4, 60.

Venegas, S. and Mysak, L. 2000. Is there a dominant timescale of natural climate variability in the Arctic? J. Clim. 13, 3413-3434.

Zhang, J., Lindsay, R., Steele, M. and Schweiger, A. 2008. What drove the dramatic retreat of arctic sea ice during summer 2007? Geophys. Res. Lett. 35, L11505, doi:10.1029/2008GL034005. 